\title{
CHILDCARE USAGE AMONG CANADIAN PRESCHOOLERS WITH EARLY OBSERVABLE DIFFERENCES
}

\author{
by \\ Tara Ouellette \\ B.A., Carleton University, 2007
}

\begin{abstract}
A thesis submitted to
the Faculty of Graduate and Postdoctoral Affairs

in partial fulfillment of the requirements for the degree of

Masters of Arts

in

Psychology

Carleton University

Ottawa, Canada
\end{abstract}

(C)2011 Tara Ouellette 
Library and Archives

Canada

Published Heritage

Branch

395 Wellington Street Ottawa ON K1A ON4 Canada
Bibliothèque et

Archives Canada

Direction du

Patrimoine de l'édition

395 , rue Wellington

Ottawa ON K1A ON4

Canada
Your file Votre référence

ISBN: 978-0-494-83077-2

Ourfile Notre référence

ISBN: 978-0-494-83077-2
NOTICE:

The author has granted a nonexclusive license allowing Library and Archives Canada to reproduce, publish, archive, preserve, conserve, communicate to the public by telecommunication or on the Internet, loan, distribute and sell theses worldwide, for commercial or noncommercial purposes, in microform, paper, electronic and/or any other formats.

The author retains copyright ownership and moral rights in this thesis. Neither the thesis nor substantial extracts from it may be printed or otherwise reproduced without the author's permission.
AVIS:

L'auteur a accordé une licence non exclusive permettant à la Bibliothèque et Archives Canada de reproduire, publier, archiver, sauvegarder, conserver, transmettre au public par télécommunication ou par l'Internet, prêter, distribuer et vendre des thèses partout dans le monde, à des fins commerciales ou autres, sur support microforme, papier, électronique et/ou autres formats.

L'auteur conserve la propriété du droit d'auteur et des droits moraux qui protège cette thèse. $\mathrm{Ni}$ la thèse ni des extraits substantiels de celle-ci ne doivent être imprimés ou autrement reproduits sans son autorisation.
In compliance with the Canadian Privacy Act some supporting forms may have been removed from this thesis.

While these forms may be included in the document page count, their removal does not represent any loss of content from the thesis.
Conformément à la loi canadienne sur la protection de la vie privée, quelques formulaires secondaires ont été enlevés de cette thèse.

Bien que ces formulaires aient inclus dans la pagination, il n'y aura aucun contenu manquant. 


\begin{abstract}
The purpose of the current research was to compare the childcare use and its influence on developmental outcomes for children who were healthy $(n=8853)$ and children with Early Observable Differences (EOD), including children with neurodevelopmental disorders (NDD; $\mathrm{n}=250$ ), externalizing behaviours (EXTBEH; $\mathrm{n}=793$ ) and both NDD and EXTBEH (BOTH; $\mathrm{n}=108$ ). Prior to the current research, it was assumed that children with EOD utilized and responded to childcare in a manner similar to HEALTHY children. This study showed that such assumptions were incorrect. In particular, ANOVA results indicated that childcare characteristics were significantly different between the health status groups but for most variables EOD children showed similar childcare use characteristics. Furthermore, unlike typically developing children, the impact that childcare had on the development of children with EOD was additional to, and in some cases, greater than the impact of family characteristics. Specifically, regression results showed that while controlling for family variables, childcare variables could predict cognitive outcomes (evaluated by the Who am I?) in children with EOD and language outcomes (evaluated by the Peabody Picture Vocabulary Test) for healthy children. Family characteristics predicted language outcomes for children who were healthy and children with EXTBEH and cognitive outcomes for children who were healthy and children with NDD.
\end{abstract}




\section{Acknowledgements}

This research was supported by Statistics Canada through access to the National Longitudinal Survey of Children and Youth. It is important to note however, that the views and findings herein are those solely of the author, and do not reflect the official position of Statistics Canada.

I would like to express my sincere appreciation to my supervisor, Dr. Amedeo D'Angiulli for his patience, guidance, support, and feedback throughout the process. Thanks also to my committee members, Dr. Stefania Maggi and Dr. Robert Coplan for their opinions, patience and support throughout, as well as my informal committee members, Dafna Kohen and Rubab Arim for their knowledge and guidance. I would also like to extend a thank-you to the Etelle Bourassa in the Psychology department for her calm reassurance.

Finally, thanks to the long list of family and friends who encouraged and supported me throughout this journey. I would not have been able to complete this project without the endless support of my husband Neil and children Ava and Naomi. To you I owe the biggest thanks. 


\section{Table of Contents}

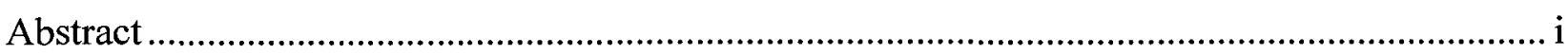

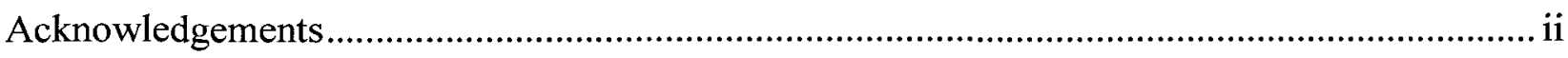

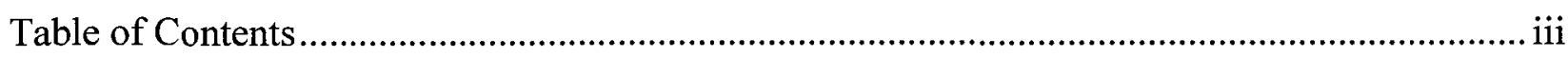

List of Tables and Figures...................................................................................................... vii

The Importance of Inclusion for Children With and Without EOD .......................................... 6

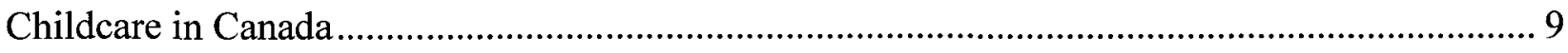

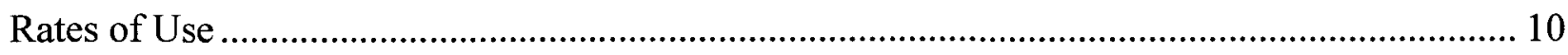

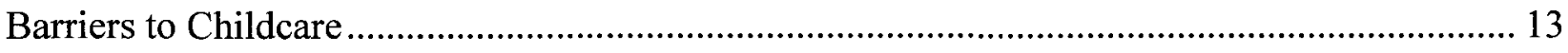

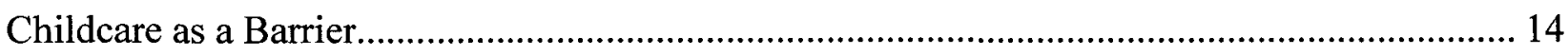

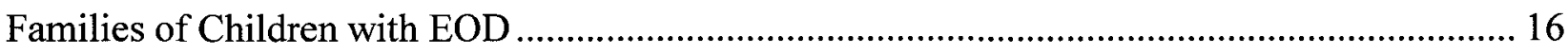

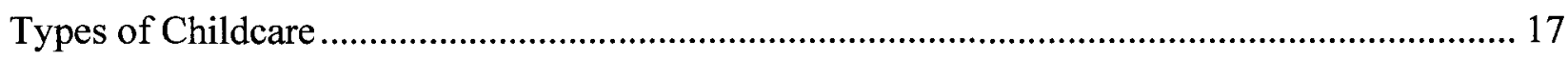

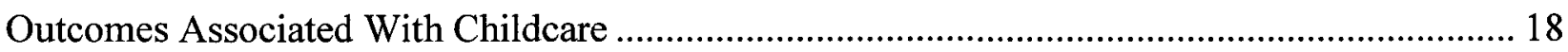

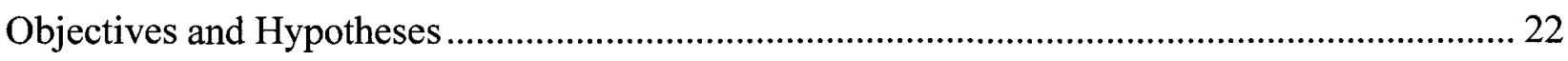

Objective 1: Differences Between Children With and Without EOD .......................................... 22

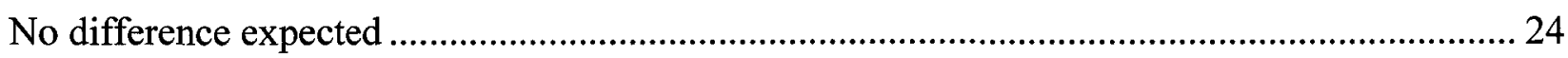

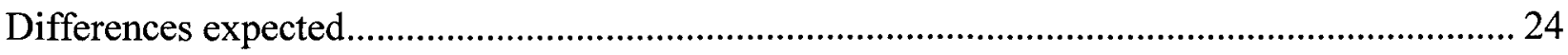

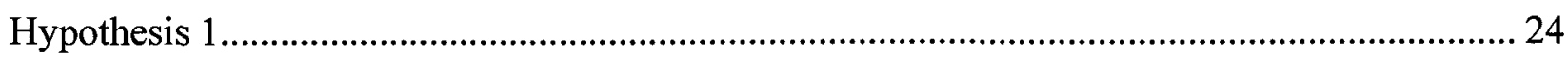

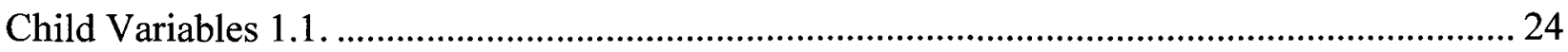

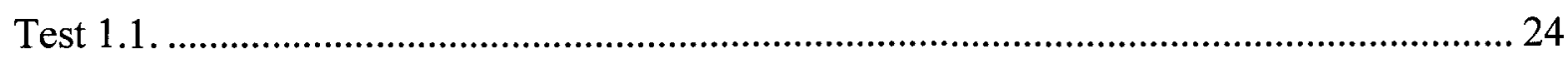

Family Variables 2.1 .

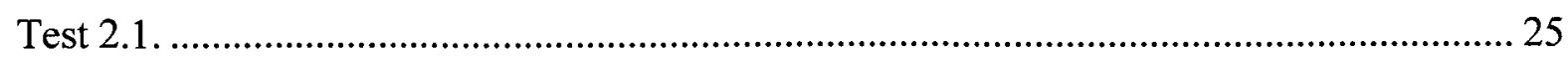

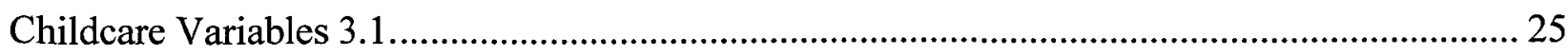


Objective 2: The Relationships Between Family and Childcare Variables and the Outcomes .... 27

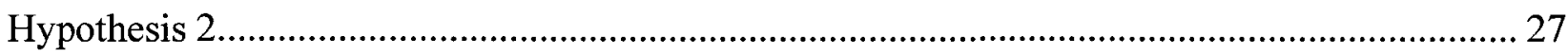

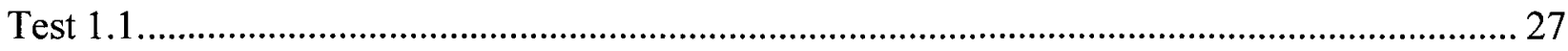

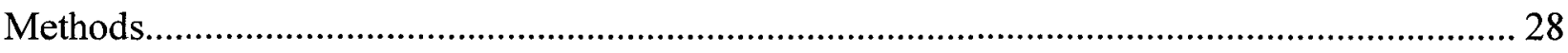

Sample

Classification of Children's Health Status and Sample Sizes...................................................... 29

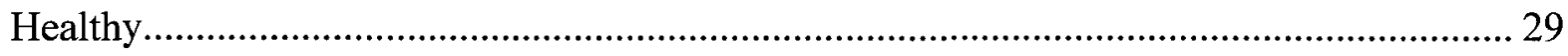

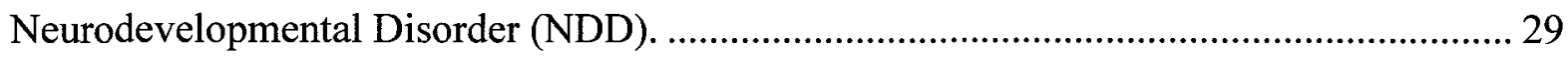

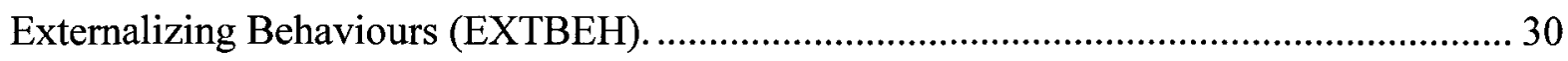

Both Neurodevelopmental and External Behaviours (BOTH)........................................ 32

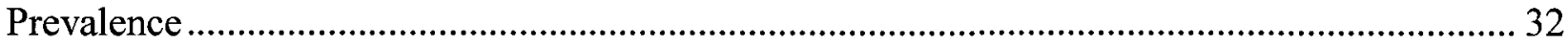

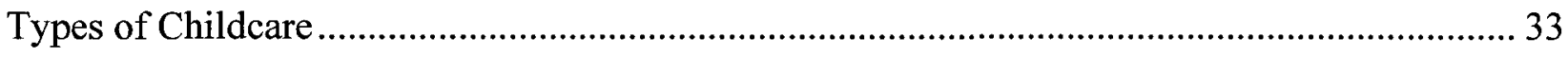

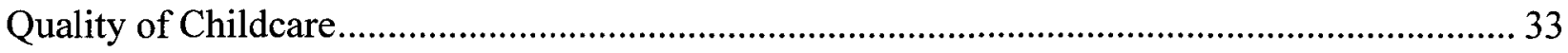

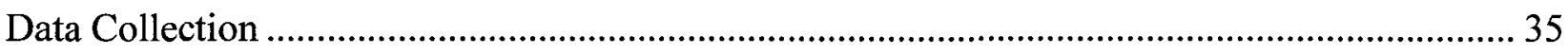

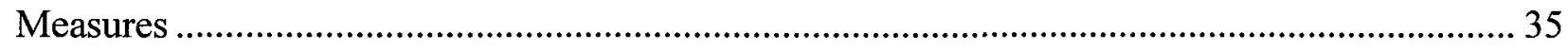

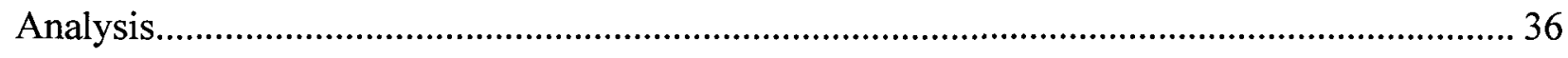

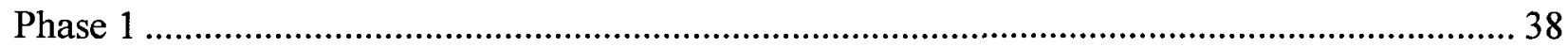

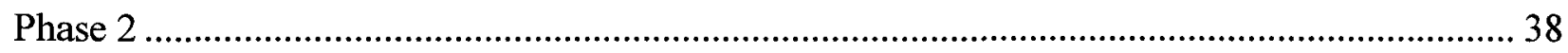

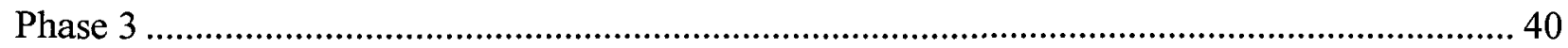

Power

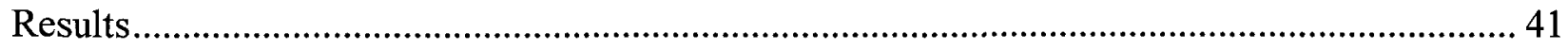

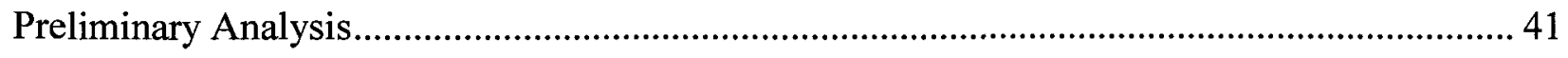


Data screening.

Assumptions.

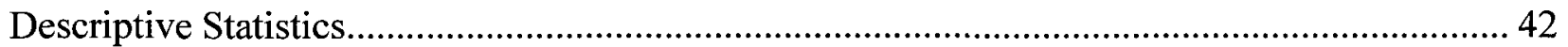

Objective 1: Differences Between Children With and Without EOD .......................................... 47

Child Variables. One-way ……..................................................................................... 47

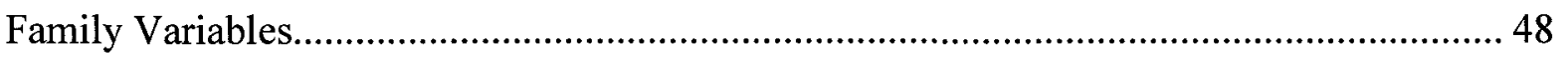

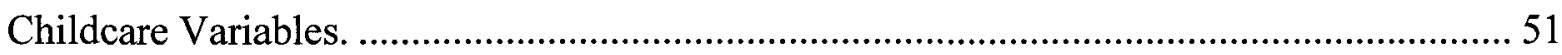

Summary of the Differences Between Children With and Without EOD .....................................5 54

Objective 2: The Relationships Between Family and Childcare Variables and the Outcomes .... 60

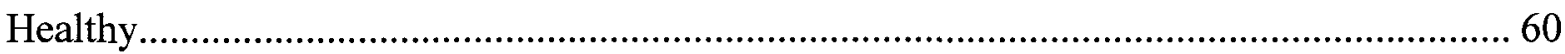

$\mathrm{NCH}$

NDD

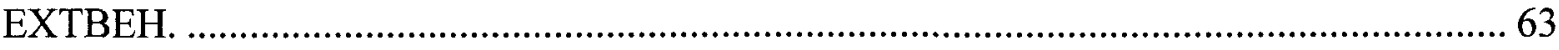

Summary of the Influence of Family and Childcare Variables on Language and Cognitive

Outcomes for Children With and Without EOD ................................................................... 64

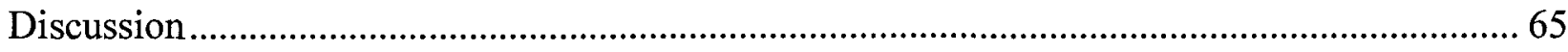

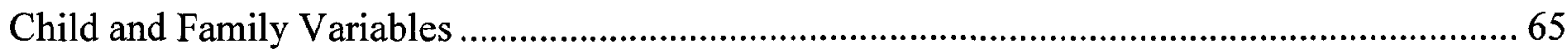

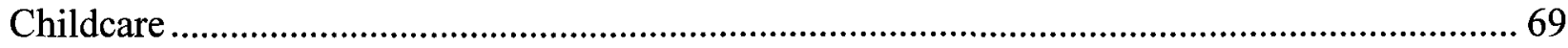

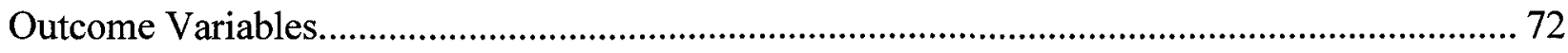

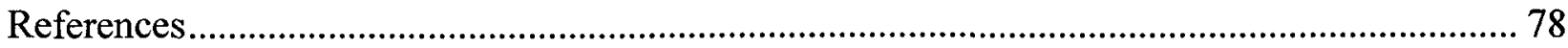

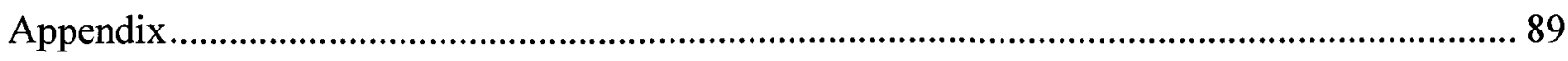

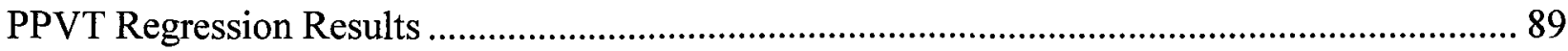




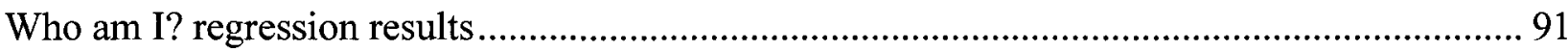




\section{List of Tables and Figures}

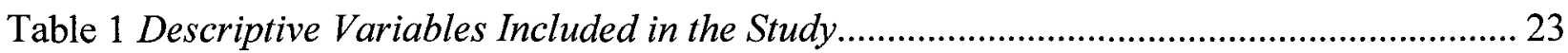

Table 2 Summary of Predictions for Differences Expected between Health Status Groups ......... 24

Table 3 Sample Sizes for the Different Health Status Groups and Outcome Measures ................ 30

Table 4 Descriptive statistics for all health status groups............................................................. 44

Table 5 Chi-square analysis: Crosstab percentages for all health status groups....................... 46

Table 6 Descriptive statistics and results of Games-Howell post hoc tests comparing the NDD to

all other groups.

Table 7 Descriptive statistics and results of Games-Howell post hoc tests comparing the

EXTBEH to all other groups.

Table 8 Descriptive statistics and results of Games-Howell post hoc tests comparing the BOTH

to all other groups.

Table 9 Descriptive statistics and results of Games-Howell post hoc tests comparing the

HEALTHY to all other groups

Table 10 Descriptive statistics and results of Games-Howell post hoc tests comparing the NCH to all other groups.

Table A1. 1 Regression of Family and Childcare variables for full model on PPVT

Table A1. 2 Regression of Family and Childcare variables for full model on Who am I? 91

Figure 1. ANOVA Comparisons. Health status group (Group) is the independent variable for each comparison.

Figure 2. Chi-Square Analysis. Health status group (Group) is the independent variable for each comparison. 39 
Figure 3. Blocked Regression Model for EOD, NCH and HEALTHY................................. 41 


\section{Childcare Usage Among Canadian Preschoolers with Early Observable Differences}

Since the 1990's, there has been an increase of mothers in the labour force (Friendly and Prentice, 2009; Shearn \& Todd, 2000) with more mothers returning to work sooner after pregnancy (Shearn \& Todd, 2000), which has created greater demand for childcare within Canada (Friendly, Rothman, \& Oloman, 1991). The focal point of research in childcare tends to include either the effects of childcare on children, the quality of childcare or the effectiveness of early childhood education and care programs within childcare settings. Typically, one line of research has considered the effects of childcare on measureable outcomes such as pro-social behaviour, aggressive behaviour, and academic behaviour. Another line of research has considered the characteristics of childcare use such as age of entry into childcare, the number of hours a child is in childcare (quantity), and the quality of the childcare that the child receives. In both lines of investigation, the majority of research involves children who are typically developing; there has been very little research on childcare-related outcomes in children with atypical development and almost no research on their characteristics of childcare use (for examples see Booth-LaForce \& Kelly, 2004; Rosenzweig, Brennan, Huffstutter \& Bradley, 2008).

Bronfenbrenner (1979) put forth the idea that human development is influenced by several different environments, conceptually this was known as the ecological systems theory, later as the bioecological systems theory (Bronfenbrenner, 2005). In his theory, Bronfenbrenner (1979) identified five environmental systems (Microsystem, Mesosystem, Exosystem, Macrosystem, and Chronosystem) that are inextricably linked to, and influence human development. Bronfenbrenner (1979) argued that it is important to understand the influence these environmental systems have on a child's development and appreciate that these environments do 
not act in isolation, rather, they constantly interact with each other. For example, a child's Microsystems might include their family, peers, and childcare. However, there would also be an interaction between family members and childcare providers, creating a family-childcare Mesosystem. In addition, a mother's education and employment status (Exosystems) might influence the other family members as well as the child's childcare environment. Bronfenbrenner (1979) also put forth that these environments influence a child's development as much as a child's development influences these environments. This theory directed a change in the way childcare was researched which was apparent in the influential research by The National Institute of Child Health and Human Development (NICHD Early Child Care Research Network, 1999).

The National Institute of Child Health and Human Development (NICHD), based in the United States, conducted a longitudinal study starting in 1991 (NICHD Early Child Care Research Network, 1999), called the NICHD Study of Early Child Care and Youth Development (Booth \& Kelly, 2002). The purpose of this study was to investigate the effects of childcare, using 1364 typically developing children from 10 different locations in a total of nine different states (Booth \& Kelly, 2002; NICHD Early Child Care Research Network, 2005). These children were enrolled at birth, following a screening procedure that eliminated any children identified as having a disability, at risk of a disability or complications at birth (NICHD Early Child Care Research Network, 2005). The NICHD Study of Early Child Care and Youth Development (SECCYD) is one of the most comprehensive and extensive bodies of childcare research to date. In part, the goal of this large scale study was to provide clarification to the previous research findings that provided conflicting results regarding the impact that childcare has on child development. To overcome the shortcomings of past research, the NICHD investigators examined the relationship between family characteristics, demographic characteristics, parental 
characteristics and childcare. In addition, they incorporated many childcare characteristics (e.g. quality, quantity, and type of childcare) within the same study, rather than examining just one at a time. Finally, when examining the quality of childcare, the investigators relied on both indirect and direct measures of quality while previous research relied only on indirect measures of quality (Eunice Kennedy Shriver National Institute of Child Health and Human Development, 2006; NICHD Early Child Care Research Network, 2005).

Despite the plethora of research involving typically developing children, the results and implications of childcare are still somewhat blurred and ambiguous. For example, some studies have noted that childcare can hinder social development, while others have noted no difference in social development (for summaries see Booth \& Kelly, 2002; Romano, Kohen \& Findlay, 2010; Sphancer, 2006). Yet other studies find that cognitive and language abilities are related to childcare, but perhaps only when the childcare was of a high quality (Booth \& Kelly, 2002).

Differently than in the research done in the US, Canadian childcare research focuses on the rates of inclusion (as examples see: Friendly \& Prentice, 2009; Irwin, Lero, \& Brophy, 2004) rather than the outcomes of children with atypical development, or the more descriptive information such as what types childcare are most often used by children with atypical development. As noted above, a large portion of the research that has focused on children with atypical development has been conducted in the United States, which identifies a gap in the literature and clear necessity for Canadian research in these areas. The differences in parental leave between the United States and Canada, (12 weeks, with several stipulations such as length of employment, and the size of the company, is available to new parents in the United States versus 15 weeks of paid maternity leave, available to the mother, and 35 weeks of paid parental leave, available to either parent in Canada; Service Canada, 2011) implies that the patterns of 
childcare use in Canada would be different from those in the United States. For example, Canadian children may enter childcare at an older age due to a longer paid parental leave. The main objective of this study is to use a Canadian nationally representative sample of preschool aged children to fill part of the gap in knowledge that currently exists in the literature, specifically, by examining the characteristics of childcare use among children with early observable differences, and the impact that childcare has on their language and cognitive outcomes.

The focus of this paper is to examine the use and influence of childcare in Canadian preschool children with early observable differences (EOD). EOD is an inclusive concept which encompasses the critical transitions of children 'at risk' of a diagnosis, such as children with externalizing behaviour (EXTBEH), as well as children with a clinical diagnosis, such as children with neurodevelopmental disorders, within the same framework. For the purposes of this study, the term EOD will be used as an umbrella term. This term encompasses children with neurodevelopmental disorders (NDD) such as children with Epilepsy, Cerebral Palsy, mental handicap ${ }^{1}$, and learning disability, children who exhibit externalizing behaviours (EXTBEH) such as children who have a difficult time settling on a task, children who get into fights, or children who tell other children not to be friends with another specific child, and those children that have both a neurodevelopmental disorders and exhibit externalizing behaviours (BOTH). If one assumes an inclusive definition of challenging behaviours (Emerson, 2001; Hemmings, 2007; Sigafoos, Arther, \& O'Reily, 2003) or the social model definition of disability (Oliver, 1983) it can be derived that indirect aggression such as vengeful behaviour, physical aggression

\footnotetext{
${ }^{1}$ The term Mental Handicap is no longer the common nomenclature within the public sector. However, this term was used within this research to remain consistent with the terminology utilized in the National Longitudinal Survey of Children and Youth (Cycle 7 - Statistics Canada and Human Resources Development Canada, 2006b).
} 
and hyperactivity present a fundamental similarity with neurodevelopmental disorders such as Epilepsy, Cerebral Palsy, Mental Handicap and Learning Disability. Indeed, from a social behavior perspective on disability (Oliver, 1983) it can be theorized that in all these cases there are differences that could become evident relatively early to parents and caregivers (and teachers). Depending on the culture, environment, or expectations, early behaviours associated with more intrapersonal psychological states such as anxiety or shyness may not be judged as undesirable, obvious or even problematic in very young children (Oliver, 1983). In some cases, issues of mental health linked with these conditions in preschool children are poorly understood and still largely underestimated, under detected or even ignored (Shakuntala Walker \& Melvin, 2011). These other conditions, although critically important, were not included in this study because they are not as easily and reliably detected through parents' reports. To confirm this, a preliminary cursory analysis of respondents, aged $0-5$, in the National Longitudinal Survey of Children and Youth (2006) diagnosed with emotional disorders showed that the prevalence of unspecific emotional problems was very small (i.e., $\mathrm{N}<50$ ) and statistically not testable. (Notice that according to the ethical and methodological policy of Statistics Canada it would not be possible to release the statistics generated from this group). Therefore, it would not be possible to reach any meaningful conclusions, at the population level, about the inclusion of children with emotional disorders in childcare or other services.

The present definition of EOD refines and extends the conceptualization that has been used in previous Canadian research using the National Longitudinal Survey of Children and Youth (Lach et al., 2009). The same database and groups were utilized in this research but with an important difference. Namely, children with disabilities here are conceptualized as a subgroup 
of children within the umbrella of EOD who have observable differences specific to the diagnosis of a chronic condition.

\section{The Importance of Inclusion for Children With and Without EOD}

As a society we know that placing individuals with EOD into institutions and washing our hands of them will not be tolerated as it violates human rights (Ferleger \& Boyd, 1980). However, it is not only the violation of human rights that demands the inclusion of children with EOD; but rather the potential positive effects for both children with and without EOD. Wolfensberger (1972) suggested that children with differences should be integrated into educational programs, specifically early childhood education (preschool), as it was thought that children with differences would learn more from their peers in an inclusive situation than they would from their peers in a segregated classroom. Furthermore, Wolfensberger (1972) put forward that integration at the preschool level would be the most ideal, as young children are not often concerned with individual differences.

Child development centres (preschools and childcare centres) adapted slowly to the notion of inclusion between the 1960's and early 1980's. By the late 1980's children with physical disabilities endured a large amount of passive time each day, rather than being included in academic events (Prentice, 2001). Children with other differences were being included on a case by case basis, usually as a result of a persistent parent or advocate. Growing amounts of research stemmed out of the concept of inclusion and questions regarding the benefits and drawbacks of inclusion were soon being studied. Undoubtedly, research has shown that inclusive settings provided benefits to both children with EOD and children without EOD (Bruder, \& Brand, 1995; Stahmer, \& Carter, 2005; Stahmer, Carter, Baker, \& Miwa, 2003) and that, at least 
in the school setting, inclusive settings were equivalent in cost or less expensive to run when compared to specialized, segregated environments (Odom et al, 2001).

In 1995, Bruder and Brand conducted a study using the Infant Toddler Environmental Rating Scale (ITERS - a scale meant to evaluate the environmental quality of centre based childcare) developed by Harms, Cryer and Clifford in 1990, to identify the difference in quality between inclusive and segregated classroom settings. The results of the Bruder and Brand study (1995) indicated that of the seven subscales in the ITERS, one scale (listening and talking) showed no statistically significant difference, one scale (adult needs) was statistically better in the segregated classrooms, while the other five subscales (furnishings, personal care, learning activities, interaction style, and program structure) were all significantly better in the inclusive classroom settings. A literature review by Odom (2004) confirmed the research by Bruder and Brand (1995) in that it identified that inclusive childcare settings appeared to be of equal quality to segregated or regular childcare settings.

Research has shown that there are other benefits for children with EOD when they are included in regular classroom and childcare centres (for a review, see Odom, 2000; Odom et al, 2004). Children with EOD in inclusive settings performed equally or better on standardized tests of development when compared to children with EOD in specialized/segregated classroom settings (Odom, 2000). Furthermore, children with EOD in inclusive settings displayed an increase in language, communication, and cognitive skills when compared to like children in segregated classrooms (Ingersoll, Schreibman, \& Stahmer, 2001; McGee, Morrier, \& Daly, 1999). Other research has identified benefits to inclusive settings that are not limited to academic benefits. In a literature review by Odom (2000) it was seen that children with EOD in inclusive settings had an increase in peer interaction and exhibited positive behavioural effects. Also, 
Ingersoll and colleagues (2001) and McGee and colleagues (1999) have shown that children with EOD demonstrated improved play and social skills when they were included in regular class settings rather than segregated class settings.

Children without EOD also benefit from being integrated in inclusive settings. Studies have shown that children without EOD that were in inclusive settings demonstrated improved social skills, fewer behavioural problems (Strain \& Cordisco, 1994 as cited in Stahmer et al., 2003) and had fewer stereotypes and prejudices (Peck, Carlson, \& Helmstetter, 1992).

Furthermore, Stahmer \& Carter (2005) conducted a study with typically developing children aged 18-30 months, who were enrolled in the Children's Toddler School, which is part of the Children's Autism Intervention Centre. This full time daycare enrolled eight children with Autism and eight children who were of typical development. Before entering the program, the typically developing children were screened using the Bayley Scales of Infant Development (BSID; Bayley, 1993), Gilliam Autism Rating Scale (GARS; Gilliam, 1995) and The Child Behavior Checklist Ages 2-3 (CBCL; Achenbach, 1992) to ensure that they did not present any developmental delays prior to entering the program. Upon exiting the program, all the typically developing children were assessed again, using the same measures, to determine if the program had any detrimental effects. The results indicated that typically developing children were more likely to score above the mean on the BSID both at entry to the program and exit from the program. In addition, there were no significant differences in the children's receptive and expressive vocabularies across time, as at both testing periods the children scored significantly above the mean on the Receptive and Expressive One Word Picture Vocabulary Test - Revised (Gardner, 1990). Finally, the typically developing children did not show any significant emotional or behavioural changes evaluated by the CBCL or changes in behavioural symptoms, 
evaluated by GARS, specifically related to Autism. This study supported the findings of Stahmer et al. (2003) where parental reports identified that there were no perceived concerns or detrimental effects of inclusive settings for children that were typically developing. It is apparent that inclusive childcare is beneficial for both typically and atypically developing preschoolers. Despite the well intended efforts, and known benefits of normalization and inclusion, there is evidence indicating that children with EOD still struggle to be included in normalized childcare settings (Buysse, Wesley, Bryant, \& Gardner, 1999; Kagan, Lewis, Heaton \& Cranshaw, 1999; Mulvihill, Rosenzweig et al., 2008).

\section{Childcare in Canada}

In Canada, as in other countries, the Convention of the Right of the Child (CRC), developed in 1989 by the United Nations (Office of the United Nations High Commissioner for Human Rights, 1989) and the Convention of the Right of Persons with Disabilities (CRPD), developed in 2007 by the United Nations and ratified by Canada in 2011(Council of Canadians with Disabilities, 2011; Office of the United Nations High Commissioner for Human Rights, 2011) are policies put in place to protect children, allowing them all the right of education and inclusion. The majority of the countries that have signed onto the CRC have shown their commitment by having mainstream or universal childcare. Mainstream or universal childcare ensures that each child, regardless of child/family characteristics such as child development, or family socio-economic status, is able to attend childcare (Friendly \& Prentice, 2009). Despite other countries such as Sweden, France, Norway, Iceland and more, seeing the importance of universal childcare, Canada has made very little effort to supply adequate amounts of accessible high quality childcare (Friendly \& Prentice, 2009; UNICEF, 2008) universally across the country. 
The province of Quebec has the only universal childcare system in Canada. Since 2000, all children aged 0-4 years of age have been able to attend childcare for $\$ 5 /$ day with fees being raised to \$7/day in 2003 (Beach, Friendly, Ferns, Prabhu \& Forer, 2009). Efforts have been made to accommodate the lack of available childcare in other areas of Canada by providing full-day kindergarten for children who are five years of age in a selection of provinces (Ontario, Quebec, Nova Scotia, British Columbia, and New Brunswick) and the Yukon Territories (Elementary Teachers' Federation of Ontario, 2008). Some provinces such as British Columbia have committed to establishing preschools (pre-kindergarten) to serve children who are aged three and four to support the transition to the education program at age five (Government of British Columbia, 2010). In addition to full-day every day kindergarten for children who are five years of age, Ontario has implemented full-day every day junior kindergarten for children who are aged four (Elementary Teachers' Federation of Ontario, 2008). This optional full-day junior and full-day senior kindergarten is said to be implemented province wide by 2014 (Office of the premier, 2011).

\section{Rates of Use}

Although it is not completely clear why there has been an increase in childcare use, it is plausible that it is related to the increase in maternal employment (Beach et al., 2009; Smith, 2002). According to the US census data, in 2002, $63 \%$ of children under the age of 5 were using some form of regular, non-parental childcare for up to almost 40 hours a week (Smith, 2002). In Canada there has been the same increase in non-parental childcare also possibly related to the sharp increase of mothers in the labour force. Only $57 \%$ of mothers were in the work force in 1992, and 65\% in 2006 (Friendly \& Prentice, 2009). Friendly and Prentice (2009) stated that in $2006,65 \%$ mothers with children aged $0-12$, were in the workforce, with the percentages of 
mothers in the workforce increasing with the child's age. According to 2002-2003 data, this increase in working mothers contributed to over half (54\%) of children aged six months to five years receiving some form of non-parental childcare (Bushnik, 2006).

The proportion of children with EOD included in any kind of childcare is relatively unknown (Buysse et al., 1999), as the rates of childcare use by children with EOD varies from study to study conceivably due to the fact that each study has frequently focused on a specific subsample of children which often diverge across studies. Some studies have used a medical model of disability (Oliver, 1990) and hence included individuals who have a diagnosed disability by a certain age, (Kelly \& Booth, 2002) or children with a range of specific disabilities such as Down syndrome (Cuskelly, Pulman, \& Hayes, 1998). Other studies have used a more social model (Oliver 1983, 1990) and therefore included individuals who were identified as 'at risk' of being diagnosed with a disability (Kelly \& Booth, 2002), or individuals with long lasting physical, mental, or emotional conditions that impact and restrict their participation in activities including learning (Brandon, 2000).

If we consider the indication of social isolation and/or exclusion from services, it is within reason to theorize that children with behaviours which are obvious and observable to others, such as physical aggression or hyperactivity, would be more likely to be excluded from services such as childcare (Emerson, 2001; Hemmings, 2007; Oliver, 1983; Sigafoos et al., 2003). More specifically, researchers have illustrated, that when compared to other children with EOD, children with EXTBEH were the most difficult to find childcare for (Brandon, 2000; Rosenzweig et al., 2008; Rosenzweig, Brennan \& Ogilvie, 2002). Preschoolers with EOD often require extra time, staff, and/or resources which might prevent them from being easily included in typical childhood/childcare settings (Andrew Fleck Child Care Services, 2008). Ordinarily, 
children who require additional resources also require supplementary funding to support their specific needs. Typically, children diagnosed by a physician or other medical specialist receive supplementary funding but, by and large, children with EXTBEH are not provided with supplementary funding (Andrew Fleck Child Care Services, 2008) as they do not bear a diagnosed condition. Thus, many childcare providers may shy away from including children with EXTBEH as the foreseeable additional expenses would be the sole responsibility of the childcare provider.

Despite the Convention of the Right of the Child and the Convention of the Right of Persons with Disabilities stating that children with EOD have the right to normalized inclusive settings, Lero, Doherty, Goelman, LaGrange, and Tougas (2000) found that there were numerous childcare centres in Canada and the United States, that did not include children with EOD at all. American based studies reported $34 \%$ of childcare centres had one or more children with disabilities enrolled (Buysse et al., 1999) and that nearly one third of parents were denied childcare due to the fact that their child had a disability (Cutler \& Gilkerson, 2002). In Canada, within the province of Manitoba, $18.7 \%$ of childcare centres had no children with EOD enrolled. The number of centres with no children with EOD enrolled reached an astounding $50 \%$ in the province of Newfoundland. However, overall, Lero et al. (2000) did report that most childcare centres had one or two children with EOD enrolled, and some provinces, Manitoba, Ontario, and Saskatchewan, had a large number of childcare centres ( $45.2 \%, 45.9 \%$ and $49.5 \%$ respectively) that had three or more children with EOD enrolled. The lack of childcare spaces available to Canadian children in general bring to eye how difficult it is to find childcare for a typically developing child, let alone a child with EOD (Friendly \& Prentice, 2009). 


\section{Barriers to Childcare}

Although finding high quality, affordable childcare can be difficult for any family (Friendly \& Prentice, 2009; Rosenzweig et al., 2008), there are undoubtedly more barriers to finding childcare when a child with an EOD is involved (Buysse et al., 1999; Kagan et al., 1999; Mulvihill et al., 2002; Rosenzweig et al., 2008). Barriers can include, but are not limited to the amount of training and experience a potential childcare provider has had with children with EOD (Kagan et al., 1999; Mulvihill et al., 2002), space limitations (Buysse et al., 1999; Kagan et al., 1999), and type of difference. For example, children with typical development usually use extended family members or childcare professionals as their main form of non-parental childcare (Sonenstein, Gates, Schmidt, \& Bolshun, 2002). However, although children with emotional and behavioural issues were most often cared for by family members they were rarely cared for by childcare professionals (Irwin, Brophy, \& Lero, 2000; Rosenzweig et al., 2008). Interestingly, Parish, Clous, Huh, and Henning (2005) found that at least in low-income families, the family structure was a better predictor of child care use than differences alone. Barriers such as limited spaces for children with EOD (Buysse et al., 1999), insufficient funding and physical space/building limitations (Lero et al., 2000) have also been listed as additional barriers to utilizing childcare if the child has an EOD. In a study by Cuskelly and colleagues (1998), parents of children with EOD identified finding appropriate care as their biggest concern, while parents of children with typical development listed cost as their major childcare concern.

Most studies converge in showing that one of the biggest limitations to including children with EOD in any form of childcare was staff training. Some research has suggested that staff training can increase a person's attitude toward inclusion (Baker-Ericzen, Mueggenborg \& Shea, 2009; Kagan et al., 1999; Mulvihill et al., 2002), and the level of confidence and competence 
child care providers' had for being able to care for a child with an EOD (Baker-Ericzen et al., 2009). This increase in attitude and level of comfort leads to increased rates of inclusion (Mulvihill et al., 2002). Furthermore, Baker-Ericzen et al. (2009) identified that individuals who attended three or more inclusion training programs had a significantly higher level of positive attitude and perceived competence than individuals who did not attend as many training programs. One study also found that childcare provider training was the strongest predictor of inclusion amongst directors, teachers and homecare providers (Essa, Benner, Burnham, Martin, Bingham, \& Allred, 2008). Even if all these barriers can be overcome, most parents, both of typically and atypically developing children only utilized childcare if they have a form of employment outside the home.

\section{Childcare as a Barrier}

Parents of children with EOD face additional concerns when finding and utilizing appropriate childcare. Although maternal employment is on the rise, when employment of parents of children with EOD is considered specifically, it was seen that the employment rate of these parents was lower than that of parents of typically developing children. More specifically, in 1999, there were fewer mothers of children with EOD employed, than all mothers (both of typically and not typically developing children) employed in the 1970s (Kagan et al., 1999). Furthermore, there was a disproportionate amount of parents of children with EOD that maintained only part-time employment (Cuskelly et al., 1998; Powers, 2003; Shearn \& Todd, 2000). Reason would suggest that a major obstacle in achieving and maintaining employment, was finding appropriate childcare (Sonenstein et al., 2002), thus, it does appear logical that due to the added barriers in finding appropriate childcare for children with EOD, that the parents of children with EOD may be forced to work fewer hours (Powers, 2003) or not at all (Kagan et al., 
1999). In particular, studies by Rosenzweig and colleagues $(2002,2008)$ found that parents of children with emotional or behavioural disorders most often commented that the difficulty in finding appropriate childcare lead to great difficulties in maintaining employment and acting on career goals. Similar results were also found by Brandon (2000) where he identified that the nature of the differences a child had influenced the availability of childcare. However, Brandon also found that other factors, such as a mother's own disability, were greater predictors of a mother's employment than having a child with EOD.

Perhaps in relation to the difficulty of maintaining employment, mothers of children with differences were more likely to hold jobs that were a lower level or lower status (Landis, 1992; Shearn and Todd, 2000), and earn less money (Powers, 2003). Parish et al. (2005) compared the use of childcare by preschool aged children with EOD from low-income families to typically developing preschool aged children. This study found that there were more children with EOD who lived in poverty situations, than children who had typical development, $28 \%$ versus $16 \%$ respectively. Although, as mentioned earlier, this study identified that family structure was a stronger predictor of the use of childcare. Single parent families, with typically developing or atypically developing children, had higher rates of childcare use (79\% and $78 \%$ respectively) than children of two parent families (between $54-59 \%$ depending on whether or not the child had EOD) (Parish et al., 2005).

The studies discussed above (Brandon, 2000; Cuskelly et al., 1998; Gopalan et al., 2008; Kagan et al., 1999; Landis, 1992; Parish et al., 2005; Powers, 2003; Rosenzweig et al., 2002; Rosenzweig et al., 2008; Sonenstein et al., 2002) did not attest to a causal relationship between a mother's employment status and the availability of childcare. In 2000, Shearn and Todd conducted a qualitative study, that although it too could not account for a causal relationship 
between a mother's employment status and the use of childcare, it did provide insight into a mother's desire to work as well as suggests some possible reasons for a mother to not participate in the labour force. In their study, Shearn \& Todd (2000) found that mothers of children with EOD acknowledged the desire to work at similar levels to mothers of children without EOD. Mothers of children with EOD listed finances as one source of motivation to finding employment. However, often when mothers of children with EOD were employed the household income was not higher than when the mother was unemployed. This was because any income they did make needed to offset the potential cost of childcare, as well as the loss of the benefits of financial government funding, suggesting this may be a large deterrent for mothers of children with EOD to enter the workforce. However, despite this lack of potential income, Shearn and Todd (2000) found that most mothers stated that earning an income, even if it produced no actual monetary gain for the household, was still desirable as it resulted in an escape from financial dependency on others and provided a social release from their daily lives.

\section{Families of Children with EOD}

Parents of children with EOD face several challenges such as being less frequently employed outside of the house (Kagan et al., 1999), and working fewer hours (Cuskelly et al., 1998; Powers, 2003), consequently making less money and leading to an increased likelihood of living in poverty when compared to parents of children with typical development (Powers, 2003). In addition, parents of children with EOD may also be more likely to be a single parent as the rates of divorce are higher in families of children with atypical development than families of children with typical development (Hartley et al., 2010; Wymbs, Pelham, Molina, Gnagy, Wilson \& Greenhouse, 2008). 
A link has been identified between maternal education and the risk of having a child that is diagnosed with a developmental disorder such that, mothers who had 12 years or less of education had a higher risk of having children diagnosed with a developmental disability (Delgado, Vagi \& Scott, 2007). Yet other studies, Rojahn et al. (1993) and Najman, Bor, Morrison, Anderson, and Williams, (1992) have not identified the same relationship between maternal education and child developmental delay. Najman et al. (1992) found that although there was a relationship between maternal education and child outcomes, it was only evident when outcomes were assessed with the Peabody Picture Vocabulary Test and not when using other tests.

\section{Types of Childcare}

If a child with typical development utilizes non-parental childcare, most commonly that childcare will be provided by an extended family member such as a grandparent, or a childcare professional such as a licensed home daycare, or a childcare centre (Sonenstein et al., 2002). For children who have EOD, it is unclear as to the most common type of non-parental childcare used. For example previous studies (Essa et al., 2008) have found that children with differences were more likely to attend childcare that was larger in size, such as centre care. Yet other research suggested that children with disabilities received the least amount of childcare in a professional childcare setting such as centres or preschool (Rosenzweig et al., 2008). In part, these inconsistent results could be related to a difference in children included in the target group. In the American based study by Booth-LaForce and Kelly (2004), it was found that children with EOD entered childcare later, had fewer numbers of hours in care, and had more childcare arrangements than children without differences. 


\section{Outcomes Associated With Childcare}

The literature concerning the effects of childcare on a child's outcomes is contradictory. Some research has identified a link between childcare and behaviour problems, such that childcare can either lower a child's level of aggression or lead to increased levels of externalizing behaviours. In addition, other research has indicated that childcare can have either a positive, negative, or deleterious effect on cognitive development. Still other research has suggested that childcare can hinder, or not hinder social development. If childcare does affect social development, this effect can be small, momentary, or discontinuous in nature (see Shpancer, 2006 for a summary of this literature). Other research also involving typically developing children, has conveyed mixed findings on whether the child's age of entry into childcare and quantity of use, had an effect on academic development such as language development and cognitive skills, and/or social emotional development such as aggression, noncompliance and problem behaviours (Booth \& Kelly, 2002). However, researchers appear to be of the same mind on the fact that high quality care specifically, is associated with fewer problem behaviours (Booth \& Kelly, 2002; Romano et al., 2010) and better cognitive and language outcomes (Booth \& Kelly, 2002; Loeb, Fuller, Kagan, Carroll, \& McCarthy as cited in Parish et al., 2005). Others have noted that children who had home environments that were poorer in quality, (Watamura, Morrissey, Phillips, McCartney, \& Bub, 2011) including lower income environments, (Votruba-Drzal, Coley, \& Chase-Lansdale, 2004), benefitted the most from high quality childcare.

Research investigating the outcomes of children with EOD that use childcare suggest that these inclusive settings can be beneficial for cognitive and social development for the children with EOD (Ingersoll et al., 2001; McGee et al., 1999; Odom, 2000; Odom et al., 2004) while at 
the same time, present no danger or detriment to typically developing children in the inclusive setting (Peck et al., 1992; Stahmer \& Carter, 2005; Strain \& Cordisco, 1994 as cited in Stahmer et al., 2003). In particular, Brandon (2000) found that the severity or seriousness of a child's difference was predictive of the hours spent in childcare. Although these results were tabulated from a sample that was nationally representative of the childcare use by mothers of children with disabilities in the Unites States, the results should be interpreted with caution as the data was collected in 1986-1988 and the use of childcare most certainly has changed since then because it is influenced by both demographic and economic factors (Parish et al., 2005).

Booth and Kelly (2002) conducted a study which documented that children who had entered childcare by 30 months of age (more than 10 hours per week and for longer than 15 months) had no difference in outcomes (mental, motor and adaptive functioning such as behaviour problems or attachment security) when compared to the children with special needs that did not have childcare at 30 months of age. It would be expected that children with EOD would not perform as well on tests as children without EOD; which is demonstrated in the research by Livingston (2010). Livingston found that children without EOD consistently outperformed children with EOD, as when compared to children with EOD, typically developing children displayed more passing grades. When taking into account the age of entry into childcare, Booth and Kelly (2002) showed that a later age of entry was beneficial for behavioural organization as well as adaptive behaviour, assessed using the Behavior Rating Scale (BRS) and the Wisconsin Behavior Rating Scale (WBRS) respectively. Finally, higher quality in childcare approached significance as a predictor of fewer problem behaviours in children. Age of entry, hours spent in care and quality of care were not significantly associated with other outcomes such as mental, motor development or attachment security (Booth \& Kelly, 2002). Fortunately, 
the quality of care that children with disabilities receive tends to be higher as centers that are inclusive tend to be of a higher quality than centers that are not inclusive; though conceivably, parents of children with disabilities seek out higher quality care environments (Buyesse et al., 1999). Nonetheless, these studies did not identify more specific descriptive information regarding the characteristics of children with disabilities that were using the childcare.

Despite there being research showing that childcare has an effect on a child's development, studies done by the NICHD acknowledged that childcare did not have as strong of an effect on a child's development as their family characteristics (Eunice Kennedy Shriver National Institute of Child Health and Human Development, 2006; NICHD Early Child Care Research Network, 2005). For example, in line with Delgado and colleagues (2007), the NICHD studies (Eunice Kennedy Shriver National Institute of Child Health and Human Development, 2006) showed that children had better language, cognitive, and social skills when their parents were more educated, and had higher incomes regardless of attending childcare. Furthermore, family characteristics were equally important to a child's well being, regardless of the quantity of non-parental childcare that the children received (Eunice Kennedy Shriver National Institute of Child Health and Human Development, 2006).

There have been three influential Canadian publications surrounding childcare use of children with EOD (Lero et al., 2000; Irwin et al., 2000, 2004). Regrettably, none of these Canadian publications focused on identifying specific descriptive information regarding the characteristics of childcare use by children with EOD. However, there is some American based literature that does break down the usage characteristics more specifically (Booth-LaForce \& Kelly, 2004). 
The study by Booth-LaForce and Kelly (2004) used childcare information produced from studies conducted by the NICHD as comparison data for the data collected from their sample of children with EOD. It was found that children with differences entered non-maternal childcare later than the comparison group of typically developing children. The average child with EOD entered non-maternal childcare at nearly 13 (12.6) months of age, while the typically developing children entered somewhere between six and seven (6.7) months of age. In addition, the children with EOD that were in childcare spent fewer hours per week in care than typically developing children, an average of 13.9 hours per week versus 15.4 hours per week respectively. There were no differences in the number of childcare arrangements between children with EOD and typically developing children. In slight contrast to other research (Essa et al.,2008; Rosenzweig et al., 2008), Booth-LaForce \& Kelly (2004) found that the most common type of childcare that children with EOD received was non-parental relative care, that is to say, for example care by a grandparent. The second most common form of care was provided by the father's/mother's partner. Centre based care, home based care provided by a non-relative such as a nanny, and childcare homes such as family daycare homes, were the third, fourth and fifth, most common types of non-parental childcare for children with EOD, respectively. Interestingly, BoothLaForce and Kelly (2004) also found that the proportion of typically developing children in childcare centres increased with the age of the child. However, this was not the case for children with EOD, as the percentage of children with EOD in childcare centres remained relatively stable even, as the child increased in age.

The purpose of this research was to extend the research by Booth-LaForce and Kelly (2004) using Canadian survey information from the National Longitudinal Survey of Children and Youth. In particular, the objectives of this research were to identify and compare the 
childcare characteristics, such as whether childcare is used or not, age of entry, quantity, quality, and number of arrangements for children, with and without EOD, in a sample representative of the population of Canadian children. More specifically, this research focused on comparing the childcare characteristics for the children within the four specific groups utilized in Lach et al. (2009): children that are considered clinically healthy (HEALTHY), children with a neurodevelopmental disorders (NDD), children with externalizing behaviours (EXTBEH), and children with both a neurodevelopmental disorders and externalizing behaviours (BOTH). In addition this study included a sample of children identified as not clinically healthy (NCH) which consisted of children who had other health issues not consistent with EOD such as asthma, allergies, or diabetes, for a total of five health status groups. Finally, the effects of childcare on children with EOD were examined by assessing vocabulary skills (language; assessed through the Peabody Picture Vocabulary Test) and cognitive skills associated with school readiness (cognitive; assessed through the Who am I?). By assessing the impact that childcare has on developmental outcomes for children with EOD, the current study will ascertain the degree to which the NICHD study, which indicated that family factors impacted a child's development more than childcare, is generalizable to the population of Canadian children with EOD.

\section{Objectives and Hypotheses}

\section{Objective 1: Differences Between Children With and Without EOD}

The initial objective was to compare the child, family, and childcare characteristics (see Table 1) for children who were HEALTHY or NCH and those that have EOD (NDD, EXTBEH, and BOTH). In what follows there is a precise break down of the characteristics (variables) that were compared, hypotheses, corresponding test questions, and predictions; to clearly 
differentiate them subheading numbering will be used. For a brief summary of the predicted differences see Table 2 .

Table 1

Descriptive Variables Included in the Study

\begin{tabular}{|c|c|c|c|}
\hline Child Variable & Childcare Variables & Family Variables & Outcomes \\
\hline Age of child & Type of childcare & Gender of PMK & Language \\
\hline Gender & In home & Maternal education & Cognitive \\
\hline Health Status & Else's home & PMK employ. Status & \\
\hline \multirow[t]{2}{*}{$N D D$} & Centre/preschool & Num hrs work & \\
\hline & & Family structure & \\
\hline$E X T B E H$ & Other & Single parent & \\
\hline BOTH & No childcare & Two parent & \\
\hline HEALTHY & Quantity (hours/week) & Household income & \\
\hline \multirow[t]{6}{*}{$\mathrm{NCH}$} & Age entered childcare & Number of siblings & \\
\hline & Num. of arrangements & & \\
\hline & Quality of childcare & & \\
\hline & Training & & \\
\hline & Licensed & & \\
\hline & Safety & & \\
\hline
\end{tabular}


Table 2

Summary of Predictions for Differences Expected between Health Status Groups

No difference expected

Age of child

Gender of child

PMK education

Number of siblings

Number arrangements

\section{Differences expected}

Income

Family structure

PMK work status

Rate of childcare use

Type of childcare

Quantity

Age of entry

Quality

\section{Hypothesis 1}

For the most part, it was expected that children with NDD, EXTBEH, and BOTH would have similar characteristics to each other, and that these characteristics would be different from children without EOD. However, some similarities between children with and without EOD were expected, these are noted in the predictions listed below.

Child Variables 1.1. The mean age of the child and gender of the child were examined for the children in each health status (NDD, EXTBEH, BOTH, NCH and HEALTHY). For a list of the child variables see Table 1.

Test 1.1. This analysis addressed the following question: Is there a difference in the age of the child and gender of the child between the different health statuses?

Prediction 1.1. It was expected that there would be no difference in the age of the children or the gender of the children in the five different health status groups. 
Family Variables 2.1. The family characteristics including characteristics specific to the family as a unit, as well as characteristics associated only with the mother or PMK, were outlined for the children in each health status group. For a list of the family variables see Table 1.

Test 2.1. This analysis addressed the following question: What are the family characteristics (family structure such as single parent or 2 parent family, household income and number of siblings currently residing in the household) and Mother/Person Most Knowledgeable (PMK) characteristics (level of education, and employment status) associated with each health status?

Prediction 2.1. Children with EOD were expected to live in households with lower household incomes than children who were HEALTHY.

Prediction 2.2. Children with EOD would be more likely than HEALTHY children, to live in single parent families.

Prediction 2.3. There would be no difference in the number of siblings currently residing in the household between the five health status groups.

Prediction 2.4. It was expected that the employment status of mothers of children with EOD would differ from mothers of children who were HEALTHY. Specifically, it was predicted that mothers of children with EOD would be less likely to be employed, and those that were employed, would work fewer hours than mothers of children without EOD.

Prediction 2.5. There would not be a difference in the PMK's level of education among children with EOD and HEALTHY children.

Childcare Variables 3.1. As with the child variables and family variables, each childcare variable was addressed between HEALTHY children and children with EOD. For a list of the childcare variables see Table 1. 
Test 3.1. This analysis addressed the following question: Is there a difference among childcare characteristics: whether or not childcare was used, the type of childcare that was used (care in the child's home by either a relative or non relative, care in someone else's home by either a relative or non relative, or care in a childcare centre or preschool), the quantity of childcare used (the number of hours per week), the number of different childcare arrangements, the age of entry, and the quality (safety of the childcare environment, formal training of the childcare provider and licensing of the childcare provider) associated with the different health statuses?

Prediction 3.1. It was expected that there would be a difference in the rates that children attended childcare among the different health statuses. Specifically, children with EOD will be less likely to attend childcare, than children who are HEALTHY. Furthermore, it was anticipated that as the complexity of the differences increased (from either NDD or EXTBEH to BOTH) the rates of childcare attendance would decrease.

Prediction 3.2. It was predicted that there would be a difference in the type of childcare used between the different health status groups such that, it was expected that children with EOD would most frequently attend childcare in a centre based program, while children without EOD would attend, almost equally, either childcare in their own home by a relative or non relative and childcare in a centre/preschool most frequently.

Prediction 3.3. It was anticipated that children with EOD would attend fewer hours of childcare per week, than children who were HEALTHY.

Prediction 3.4. Children with EOD were expected to have a similar number of different childcare arrangements as children that were HEALTHY. 
Prediction 3.5. It was expected that there would be a difference in the age of entry to childcare between the different health statuses, such that children with EOD would enter childcare at an older age than children without EOD.

Prediction 3.6. It was expected that children with EOD would attend childcare that was of a higher level of quality than children who were HEALTHY.

Objective 2: The Relationships Between Family and Childcare Variables and the Outcomes

The final objective examined the relationship between family variables and child developmental outcomes in language, evaluated by the PPVT (Dunn \& Dunn, 1981), and cognitive domains, evaluated by the Who am I? (de Lemos \& Doig, 2000), for children who were HEALTHY, NCH and children with EOD. The relationship between childcare variables and child developmental outcomes in language, evaluated by the PPVT (Dunn \& Dunn, 1981), and cognitive domains, evaluated by the Who am I? (de Lemos $\&$ Doig, 2000), for children who were HEALTHY, NCH and children with EOD were also examined.

\section{Hypothesis 2}

It was anticipated that when the family variables were controlled for within the same model as the childcare variables, the relationship between the childcare variables and the outcomes would be different for children with and without EOD (Eunice Kennedy Shriver National Institute of Child Health and Human Development, 2006; NICHD Early Child Care Research Network, 2005).

Test 1.1. This analysis addressed the following question: Can the childcare variables be used to predict the outcome variables for children who were HEALTHY or NCH as well as children with EOD, while holding constant all family variables? 
Prediction 1.1. It was anticipated that while holding constant all family variables, the childcare variables would impact both outcomes (language and cognitive) differently for children with and without EOD. Specifically, the childcare variables would account for a significant proportion of variance in both outcomes (language and cognitive) in children with EOD but not for HEALTHY and NCH children.

Prediction 1.2. It was anticipated that quality of childcare would contribute the most unique variance above and beyond all other childcare variables for both the outcome measures (PPVT and Who Am I?) for all health status groups.

\section{Methods}

\section{Sample}

The overall sample size of the children in cycle 7 (2006) was 37,645 ranging in age from 0-22 years, although this study only considered children aged $0-5^{2}$. In total, there were 11504 children aged 0-5 in the NLSCY cycle 7 (2006) which will comprise the sample of children for the current study (Statistics Canada and Human Resources Development Canada, 2006a) (See Table 3 for a further breakdown of the sample sizes).

${ }^{2}$ The age variable in the NLSCY captures the age of the child only in years rather than in months. Therefore, there are no children actually aged zero in the study. More accurately the children labeled as zero years old are in fact children between the ages of zero months and 12 months. 


\section{Classification of Children's Health Status and Sample Sizes ${ }^{3}$}

Healthy. In this study, healthy children were children that had the absence of any chronic condition, and were not above the HUI cutpoint criteria. These children were included in the study as a representative sample of typically developing children and as a comparison group. Of the 11504 children aged 0-5 in the sample, 8853 were identified as healthy. There were an additional 1484 children identified as 'not healthy', who had a form of a chronic condition not utilized in this study, such as asthma, or diabetes etc. These children comprised the group identified as not clinically healthy $(\mathrm{NCH})$. See Table 3 for sample sizes.

Neurodevelopmental Disorder (NDD). The group identified as NDD was comprised of children who had Epilepsy, Cerebral Palsy, Learning Disabilities, and/or Mental Handicap or a score above the Health Utility Index cutpoint (Feeny et al., 1995). Children were identified as belonging to the group identified as NDD if they had any one, or more than one of the above mentioned chronic conditions (Epilepsy, Cerebral Palsy, Learning Disability, and Mental Handicap). In addition to children with an official diagnosis, the HUI cutpoint (Feeny et al., 1995) was used to identify children that may belong to the group labeled as NDD. To determine

3 Similar to the approach taken by Lach et al. (2009), children with a chronic condition such as epilepsy, cerebral palsy, mental handicap or learning disability as well as children that had conditions that might be associated with a more specific functional impairment identified by the Health Utilities Index (HUI) (Feeny, Furlong, Boyle \& Torrance, 1995) was used to identify children with neurodevelopmental disorders. (By including children above a certain cutpoint on the HUI, approximately 800 additional children were included in Lach et al. study (2009); almost double the number of children that would have been included in the study had only the children with an official diagnosis of a chronic condition been included.) Also, the presence of externalizing behaviour was identified by the presence of any one or more of the following: hyperactivity/inattention, conduct disorder/physical aggression, and/or indirect aggression. Children falling in this category were defined as the EXTBEH group. Of course this conceptualization does not exclude that children with differences might also have additional externalizing behavioral challenges not specifically linked with their diagnosis. The final group (BOTH) consists of children identified as having both a neurodevelopmental disorder and externalizing behaviours. The current study will use this classification approach to identify children with EOD (NDD, EXTBEH and BOTH). 
a cutpoint, each participant was given a score in each of four different areas; speech, dexterity, ambulation, and cognition. Then, using only the children that were already professionally diagnosed with a disability Epilepsy, Cerebral Palsy, Learning Disability, and Mental Handicap, the mean HUI score for each area was calculated (Lach et al., 2009). Finally, any child that scored above the mean in any one or more areas, was identified as above the cutpoint on the HUI, and thus was counted in the group identified as NDD. Research has shown (Lach et al., 2009) the children identified as above the cutpoint on the HUI, are at risk of being diagnosed later in life. By including children with a diagnosed chronic condition and those above the HUI cutpoint there were 250 children aged 0-5 included in the group labeled NDD.

Table 3

Sample Sizes for the Different Health Status Groups and Outcome Measures

\begin{tabular}{cccc}
\hline Group & $\mathrm{N}$ & Children with scores & Children with scores \\
& & on the PPVT & on the WHO am I? \\
NDD and BOTH & $798^{\mathrm{a}}$ & 251 & 403 \\
EXTBEH & 8853 & 2113 & 2102 \\
Healthy & 1484 & 476 & 468 \\
Not healthy & & & 403 \\
\hline
\end{tabular}

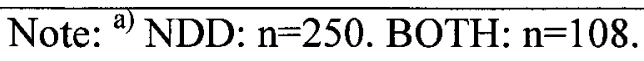

Externalizing Behaviours (EXTBEH). In the behaviour section of the NLSCY there was a series of questions in which children were given a score on a scale ranging from anywhere between zero and 10,12,14 or 16 depending on the variable of interest. For the purposes of this 
study, the children identified as having an EXTBEH were any children with a score that was two standard deviations above the mean on one or more of the EXTBEH variables used to evaluate a child's behaviour in the following areas: indirect aggression, physical aggression, and hyperactivity-inattention. Such an extreme cutoff was used as this top approximately $2 \%$ of the sample, although not officially diagnosed at this age, run the risk of being diagnosed later in life. As such, the children identified as EXTBEH, are in fact, children 'at risk' of a diagnosis as opposed to children who have a formal professional diagnosis. It is known that children with EXTBEH are often undiagnosed or diagnosed only once they have started school (Lach et al., 2009). As the children in this study are below school age, it is within the realm of possibility that although they have not yet been officially diagnosed, they are at odds of being diagnosed later in life.

The variables used to determine EXTBEH are parent reports on their child's behaviour, which have known drawbacks. Winsler and Wallace (2002) conducted a study using preschool aged children which identified that a parent's report of their child's behaviour, was at best, modestly correlated with a teacher's evaluation of the same child's behaviour. More specifically, parent's reports were found to overestimate the externalizing behaviour problems of their child when compared to the teacher's report of externalizing behaviour problems. Furthermore, it was found that a teacher's evaluation of a child's behaviour was more in line with independently observed behaviour. As it has been shown that parent's can overestimate their child's externalizing behaviour problems, this study identified children as having an externalizing behaviour only if the score they received on the EXTBEH variable was in the top $2 \%$. This way the number of children with externalizing behaviours would not likely be overestimated, as it might if the top 5\% were used. Furthermore, the medical world uses two standard deviations 
from the mean as the criteria for a diagnosis (Campbell, 2005). There were 793 children aged 0-5 that met the criteria to be included in the group labeled as EXTBEH, making this the largest group of children with EOD in the study.

Both Neurodevelopmental and External Behaviours (BOTH). For an element of complexity, children with both external behaviours as well as neurodevelopmental disorders were included in this study. Childcare is a tricky situation for typically developing children, or children with only one difference/atypical form of development. The issue is likely to be manifested when other levels of complexity exist such as multiple diagnoses or multiple forms of atypical development. Of the 11504 children aged 0-5 in the NLSCY cycle 7 (2006), there were 108 children with BOTH a NDD and an EXTBEH.

\section{Prevalence}

The Participation Activity Limitation Survey (PALS) (Statistics Canada, 2006b), a postcensal survey conducted in 2006, which used the World Health Organization's (WHO) definition of disability, identified that $3.7 \%$ of the population aged $0-14$ had some form of activity limitation due to a disability. In PALS people were self identified, if over the age of 15, or identified by their parents if under the age of 15 , so the rates of disabilities are subjective. The types of disabilities considered in PALS were grouped into 11 categories depending on age. Children aged 0-4 could be identified with one of the following types of disability: hearing, vision, chronic health conditions, developmental delay, and disability of an unknown nature while children aged 5-14 could be identified with one of the following 10 types of disabilities: hearing, vision, speech, mobility, dexterity, learning, developmental disability or disorder, psychological, chronic health conditions, and disability of an unknown nature. 
Between 2001 and 2006, PALS (Statistics Canada, 2006b) reported a 1.9\% increase in prevalence rates, with part of this increase being accounted for by differences in the way disabilities are viewed and reported. It can be expected that the rates of disability identified in this study will be slightly different than those calculated in 2006 by PALS as this study includes children identified on the HUI as well. When just children with EOD are considered, the prevalence rates in this study are $10 \%$, however, when including children that are $\mathrm{NCH}$, the prevalence rates increase to $22 \%$. Both rates are above the rates outlined above. The children identified as BOTH (10\%) in this study fit within the expected range of 10-20\% (Allen, 2008).

\section{Types of Childcare}

There is a great deal of overlap in the types of childcare that children can be enrolled in, for this reason the types of childcare were grouped according to previous research (Parish et al, 2005; Romano et al., 2010). The types of childcare for this study were classified as: 1) childcare that occurs in the home of the child, either by a relative or a non-relative such as a nanny; 2) childcare that occurs in a home other than that of the child, this too can be either by a relative or a non-relative; or 3) childcare that occurs within a childcare centre (Romano et al., 2010).

\section{Quality of Childcare}

Cycle 7 of the NLSCY had very limited questions pertaining to the quality of the childcare arrangement. In previous versions of the NLSCY (Cycle 4), both structural and process quality could be assessed. In Canada, all childcare centres are licensed and therefore regulated, meaning that the training of staff, the adult to child ratio, building safety and other operating and structural aspects, must meet regulation standards. However, these standards do not exist in home childcare placements unless the home childcare is licensed. The questions that addressed quality in cycle 7 pertained to structural quality, that is, they addressed the safety of the childcare 
environment, the training/education of the staff, and the licensing of the childcare environment/provider.

For this study, the quality of childcare was determined by whether or not the childcare environment(s) were rated 'safe' by the PMK, whether or not the childcare provider had formal training, and finally, whether or not the childcare environment/provider was licensed. Each of these three variables was given a score of one, if the statement was true. For example, if the respondent answered "yes" to the question "To your knowledge, does your main care provider have any training in early childhood education, or child care, at the college or university level?" (Statistics Canada and Human Resources Development Canada, 2006b) that participant received a score of one for the training portion of the quality question. Each quality question was then added together, to give a final quality score ranging between $0-3$, with three representing the highest level of quality. Children who were not in childcare did not have a quality score assigned; as such they were not included in the analysis.

As centre's are monitored facilities in Canada and thus, are required to meet safety guidelines, they must be licensed, and a certain percentage of the staff must have formal training in childcare, it was anticipated that centres would have the highest quality rating. Home based childcare, either by a relative or non-relative, in the child's own home, or in another person's home, is not monitored or regulated unless the childcare provider is licensed, which is optional. As a result, home based childcare providers may not have official training in childcare, and the safety standards may not be monitored, resulting in a potentially lower quality rating for home based care, than centre based care. 


\section{Data Collection}

The childcare information obtained in the NLSCY was within the Child component of the survey. This section was completed by the Person Most Knowledgeable (PMK), in virtually all cases this was the mother or the equivalent female family figure. The PMK respondents were $91.5 \%$ female, of which $90.1 \%$ were the biological mothers while the remaining $1.4 \%$ consisted of adoptive mothers $(0.5 \%)$, step mothers $(0.1 \%)$, foster mothers $(0.1 \%)$ and other related females such as aunts or grandmothers $(0.7 \%)$. The first cycle of the NLSCY was conducted in 1994 and additional cycles of data collection occurred every two years thereafter. Cycle 7 of the NLSCY (2006/2007) was used due to the fact that it was the most recent data available at the beginning of this study.

\section{Measures}

Predictor variables included in the current study consisted of information about the child, the family and the childcare. The child, family, and childcare variables are presented separately in Table 1.

The outcome variables, language and cognitive, were assessed through the Peabody Picture Vocabulary Test (PPVT) (Dunn \& Dunn, 1981), and the Who am I? (de Lemos \& Doig, 2000) test respectively. The PPVT was designed to measure receptive vocabulary in children, while the Who am I? was designed to measure a child's developmental level (Statistics Canada, 2006a) and readiness for academic experiences by assessing cognitive processes fundamental to early literacy and early numeracy skills (de Lemos \& Doig, 2000). The correlation between the PPVT and Who am I? is low $(r=.1)$ indicating that these two tests target different skill sets (de Lemos \& Doig, 2000). The number of children who responded to the PPVT and Who Am I? are listed in Table 1. 
The PPVT is a direct measure test administered by the NLSCY data collectors, to children who were four or five years of age, it was completed by the child and was computer assisted. Each child was presented with a stimulus word and was then prompted to identify a picture which best corresponded to the stimulus word (Dunn \& Dunn, 1981; Statistics Canada, 2006a). It has a high rate of internal consistency (Cronbach's alpha $=.95$ ) and high validity when compared to the Wechsler Intelligence Scale for Children (WISC-III VIQ) for verbal ability ( $r=$ .91) (Dunn \& Dunn, 1981). This test is easily adapted for children with differences, including but not limited to children who are non-verbal and developmentally delayed, making it an ideal measure of vocabulary for children with EOD. Although this test is appropriate to assess a child with EOD, the norms have not been recalculated for this special population (Dunn \& Dunn, 1981).

Children aged four and five also participated in the Who am I? (de Lemos \& Doig, 2000), another direct measures test completed on paper by the child. The full version of the Who am I? requires each child to draw a picture of them self, copy shapes such as circles, crosses, squares, triangles and diamonds, as well as independently write letters, numbers, words, and a sentence. The drawing task was eliminated in the NLSCY cycle 7 and thus children had scores for only two scales; copying and symbols (Statistics Canada, 2006a). The norms for this test have not been recalculated for special populations. The test has high levels of reliability (Cronbach's alpha $=.91)$, and moderate levels of validity when compared to other tests of school readiness (validity ranges between $r=.4-.6$ ) (de Lemos \& Doig, 2000).

\section{Analysis}

There is a gap in the literature regarding children with EOD and their childcare use, making it essential to ascertain basic information regarding the characteristics of this 
subpopulation of children. The information regarding the child, childcare and family characteristics were addressed in objective one, through the use of descriptive and inferential statistics. In addition, multiple regression analysis was used to determine if specific family variables and childcare variables were able to predict scores on the language (PPVT) and cognitive (Who am I?) outcome measures. Regression analysis was performed for only four of the five health status groups (NDD, EXTBEH, NCH and HEALTHY), as the BOTH group did not have enough respondents to ensure anonymous analysis, and was therefore not permitted by Statistics Canada. However, to ensure that all the children were included, the children in the BOTH group were absorbed into the NDD group as this was the smallest health status group used in the regression analysis and all children in the BOTH group had an NDD as well.

Data analysis occurred in three major parts, with each part containing different tests such as preliminary analysis, univariate tests, and multiple regressions. Phase one consisted of preliminary analysis such as data cleaning, as well as checks for multicollinearity and assumptions. Phase two consisted of 14 univariate tests (Analysis of Variance and Chi-square) using Simes (1986) correction in order to control for the number of false positives that might have otherwise occurred due to the large number of comparisons. Using Simes, in order to assess significance of each comparison, the obtained $p$ values were listed in order from smallest to largest. Then the critical value was calculated based on the number of comparisons, the ranked $p$ value and the desired family wise alpha. Finally phase three consisted of multiple regressions. Each health status group (NDD, EXTBEH, NCH and HEALTHY) had one regression for each outcome (PPVT and Who Am I?). All analysis used weights provided by Statistics Canada, which were normalized to account for the probability of a child aged 0-5 being sampled, and for non-response, which allowed for a more accurate representation of the population. 


\section{Phase 1}

A missing values assessment was run to determine if the values that were missing, were missing completely at random or if there was a relationship between the missing values; this analysis identified the percentage of missing values for each variable of interest. If the Little's MCAR value was significant $(p<0.05)$, then it was assumed the values were not missing completely at random. In another analysis, the assumptions of normality, linearity, independence and homoscedasticity were evaluated. Furthermore, discrepancy, leverage, and influence were measured using Cooks's distance (Tabachnick \& Fidell, 2007). Potential multicollinearity of the variables was tested with the Variance Inflation Factor (VIF) test and tolerance. The VIF number is an indicator of how far the estimated standardized regression coefficients are from the true standardized regression coefficients, indicating an inflated estimated regression coefficient variance when compared to the estimated regression coefficients that would be obtained if the variables were not related. If the VIF is more than 10 , it was considered that multicollinearity existed (Kutner, Nachtsheim, Neter, \& Li, 2005). The tolerance limit used was 0.2 (Tabachnick \& Fidell, 2006) such that variables with a tolerance lower than 0.2 were considered highly correlated, and therefore, were not added to the regression models. As an additional check of association, Pearson's correlation between the variables was also used. If there were variables that were highly correlated with each other, and the VIF and tolerance indicated a similar high correlation, then all the correlated variables were not added to the regression models, instead the variables that were used in the regression models were determined by the effect size calculated in phase two.

\section{Phase 2}

For all of the continuous variables, such as quality of childcare, and household income Analysis of Variance (ANOVA) was conducted, as well as a calculation of the effect size. The 
resulting eta ${ }^{2}\left(\eta^{2}\right)$ was transformed into $r$ which was then be used to determine the Cohen's effect size (small .1, medium .3, or large .5) (Cohen, 1988). The independent variable for each ANOVA was the child's health status variable (Group), while the dependent variables changed for each ANOVA. (See figure 1).

In addition to the continuous variables, there were several categorical variables such as type of childcare. For these variables, the effect sizes were also calculated; however, a chi-square analysis was conducted. The resulting phi $(\varphi)$ was transformed into $\mathrm{r}$ which was used to determine the Cohen's effect size (small .1, medium .3, or large .5) (Cohen, 1988). Each chisquare had the health status (Group) as the independent variable as well as one of the following dependent variables: gender of child, maternal employment, family structure, and type of childcare (see figure 2).

Figure 1. ANOVA Comparisons. Health status group (Group) is the independent variable for each comparison.

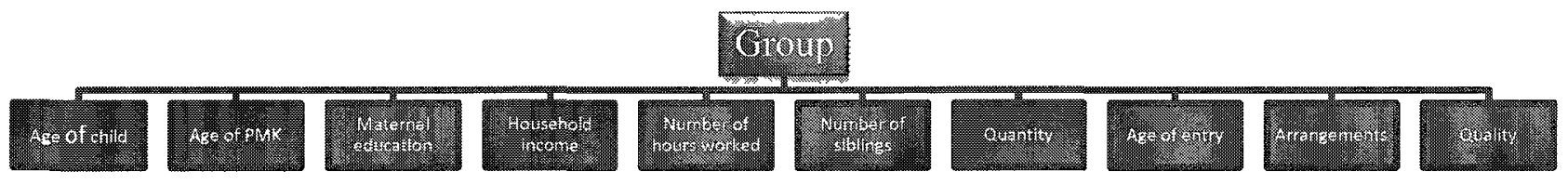

Figure 2. Chi-Square Analysis. Health status group (Group) is the independent variable for each comparison.

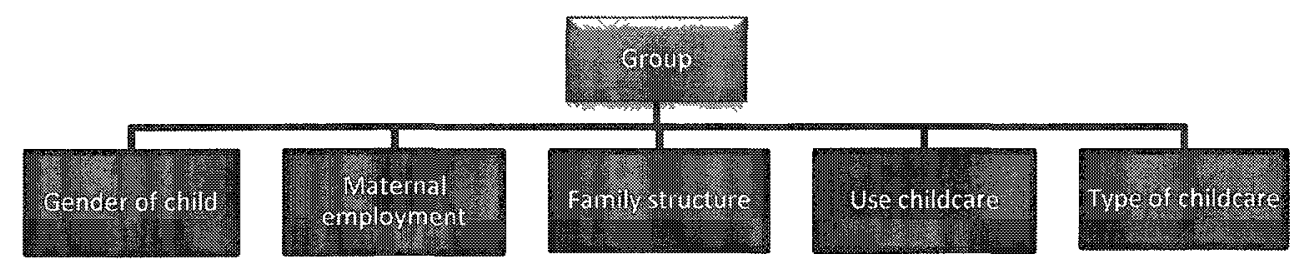




\section{Phase 3}

A series of eight regressions were in this phase of analysis, with two regressions per health status group; one for each of the language and cognitive outcomes. Each health status group had all the family variables entered (block 1), and all the childcare variables entered (block 2) to identify the amount of variance in each outcome (PPVT and Who am I?) variable that was accounted for by the childcare variables when the family variables were controlled for (See figure 3).

\section{Power}

Based on the power calculations outlined in Green (1991), with the potential 15 variables and two outcomes, a total of 17 possible predictors, a sample size of 1195 would be needed for a small effect, 159 for a medium and 68 for a large effect assuming a Power of .80 $($ alpha $=.05)($ Green, 1991). Assuming all 17 predictors were used, and a small effect size, with a Power of .80 was desired, this study would require nearly 1200 children. Given the large sample of children in the NLSCY cycle 7, of children aged 0-5 years (Statistics Canada and Human Resources Development Canada, 2006a); obtaining the necessary 1200 children for the current study was achievable. However, since some variables might not be included, the maximum number of predictor variables might decrease, which would result in a smaller sample size being needed for the same effect size (Green, 1991). For example, if only seven predictor variables were used, a sample size of 775 would be needed for a small effect, 103 for a medium and 44 for a large effect assuming a Power of $.80($ alpha $=.05)$. 
Figure 3. Blocked Regression Model for EOD, NCH and HEALTHY.

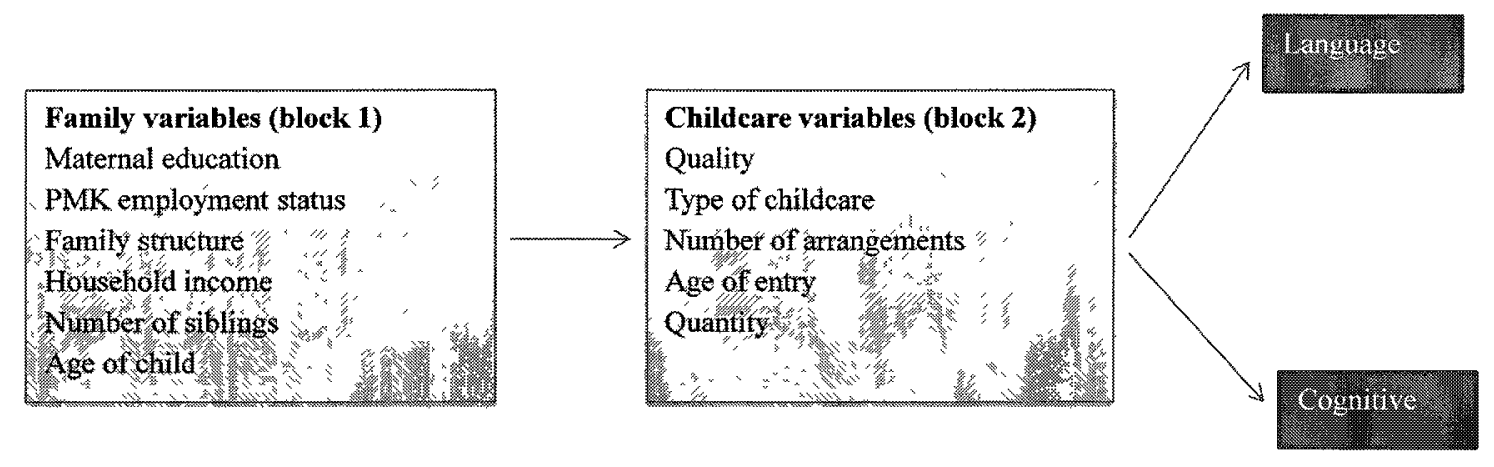

\section{Results}

\section{Preliminary Analysis}

Data screening. Missing values analysis identified that the missing values were not missing completely at random (Little's MCAR test $p<.000$ ). However as none of the variables had more than $5 \%$ missing data no data imputation was used. Scores on each variable were converted to $\mathrm{z}$ scores in order to identify any individuals that had scores outside of 3 standard deviations from the norm. As all the outliers fell within the expected or reasonable rate of outliers (less than 2\%, see Cohen, Cohen, West, \& Aiken, 2003; Tabachnick \& Fidell, 2001) it was not necessary to transform values to within three standard deviations from the mean. Multivariate outliers were determined as such if Mahalanobis distance was greater than the cutoff value determined for Mahalanobis distance at $p<.001$ (Stevens, 2002). Results from the Mahalanobis distance test showed that within the BOTH group, there was one multivariate outlier, however, as there was only one case, it was not adjusted. Cook's distance was used to determine the influence, there were no Cooks distance $\left(d_{i}\right)$ values which exceeded the cutoff value of $d_{i}>1$ (Kleinbaum, Kupper, Nizam \& Muller, 2008; Stevens, 2002; Tabachnick \& Fidell, 2007). The degree to which variables were correlated was tested using Variance Inflation Factor (VIF) and Tolerance (TOL). In all cases the VIF was lower than 10 (Kutner et al., 2005) and 
TOL was greater than 0.2 (Tabachnick \& Fidell, 2007) identifying there was no presence of multicollinearity.

Assumptions. As reflected by Kolmogorov-Smirnov statistic, all of the continuous predictor variables violated skewness, kurtosis, or both, only mildly and therefore the violation of the assumption of normality was modest. When we considered the outcome measures, we found that the Who am I? slightly violated skewness but kurtosis was within acceptable range, while the PPVT violated kurtosis but skewness was within acceptable range. However, the tests used in this study are robust to the degree of violation of normality we detected. Levene's test identified that all variables except the age of the PMK, quality of childcare, and the number of hours worked by the PMK violated the assumption of homoscedasticity. In order to ensure that any significant ANOVA and regression results could still be identified as significant even though the assumption of homoscedasticity was violated, a Welch statistic was calculated. As the Welch statistic was significant for all the variables, the significant results involving variables that violate the assumption of homoscedasticity can still be interpreted as significant findings. Linearity and independence were verified through the use of scatterplots and the Durbin-Watson statistic respectively. In addition to checking the assumptions listed above for ANOVA and regression, we verified the assumptions for chi-square analysis and we found they were met.

\section{Descriptive Statistics}

See Table 4 for a complete list of the descriptive statistics presented in the following sections. This study was conducted with 11504 children aged $0-5(M=2.51, S D=1.708)$ with the gender of the children approximately equal ( $n=5611$ female). Nearly half $(45.7 \%)$ of the children in the study had one other sibling that they currently lived with. The majority of the PMK respondents were female ( $n=10694$ female) and were aged 15-71 $(M=32.94, S D=5.968)$. 
The education level for the PMK ranged from less than a secondary education to completion of post secondary education, with more than half $(60.9 \%)$ of the PMK's being post secondary graduates. More than two-thirds of the PMK's were employed (70\%) and worked on average between 30-39 hours per week. 
Table 4

Descriptive statistics for all health status groups

\begin{tabular}{|c|c|c|c|c|c|c|c|c|c|c|c|c|}
\hline & \multicolumn{2}{|c|}{ Grand } & \multicolumn{2}{|c|}{ NDD } & \multicolumn{2}{|c|}{ EXTBEH } & \multicolumn{2}{|c|}{ BOTH } & \multicolumn{2}{|c|}{ HEALTHY } & \multicolumn{2}{|c|}{$\mathrm{NCH}$} \\
\hline & Mean & $\mathrm{SD}$ & Mean & $\mathrm{SD}$ & Mean & SD & Mean & SD & Mean & SD & Mean & $\mathrm{SD}$ \\
\hline Age of child & 3.490 & 1.708 & 4.330 & 1.012 & 3.650 & 1.132 & 4.480 & 0.664 & 2.300 & 1.693 & 2.690 & 1.665 \\
\hline Age of PMK & 33.494 & 5.968 & 34.460 & 5.631 & 33.490 & 6.237 & 34.390 & 5.469 & 32.750 & 5.948 & 33.380 & 5.938 \\
\hline PMK education & 3.190 & 1.042 & 3.310 & 1.018 & 3.230 & 1.108 & 2.790 & 1.189 & 3.370 & 1.014 & 3.250 & 1.054 \\
\hline Number of siblings & 1.206 & 0.980 & 1.270 & 0.999 & 1.290 & 0.933 & 1.380 & 0.916 & 1.180 & 0.993 & 0.910 & 0.946 \\
\hline Hours worked & 4.028 & 1.231 & 3.870 & 1.184 & 4.120 & 1.294 & 4.100 & 1.003 & 3.990 & 1.254 & 4.060 & 1.195 \\
\hline LICO & 1.339 & 1.012 & 1.450 & 0.926 & 1.295 & 1.058 & 0.852 & 0.879 & 1.569 & 0.998 & 1.527 & 0.998 \\
\hline Number of arrangements & 1.120 & 0.399 & 1.060 & 0.251 & 1.140 & 0.411 & 1.150 & 0.481 & 1.130 & 0.409 & 1.120 & 0.386 \\
\hline Quantity & 1.920 & 0.796 & 1.620 & 0.728 & 2.000 & 0.747 & 1.850 & 0.833 & 2.000 & 0.799 & 2.130 & 0.791 \\
\hline Age of entry & 0.876 & 0.810 & 0.940 & 1.067 & 0.930 & 0.788 & 0.920 & 0.849 & 0.820 & 0.793 & 0.770 & 0.811 \\
\hline Quality & 1.671 & 0.682 & 1.545 & 0.587 & 1.656 & 0.629 & 1.739 & 0.695 & 1.725 & 0.674 & 1.690 & 0.709 \\
\hline
\end{tabular}

Note: ${ }^{\mathbf{a}} 1=$ less than secondary education, $2=$ secondary graduate, $3=$ some post-secondary, $4=$ post secondary graduate, $5=$ other. $^{\mathbf{b}} 1=$ less than 10 hours, $2=$ =between 10-19 hours, $3=$ between 20 -29 hours, $4=$ between $30-39$ hours, $5=$ over 50 hours. ${ }^{\mathbf{c}} 0-0.9=$ very low income, $1.0-1.9=$ low income, 2.0-2.9=moderate income, 3 or more $=$ high income; ${ }^{d} 1=1$ childcare arrangement, $2=2$ childcare arrangements, $3=3$ childcare arrangements,

$4=$ more than 4 childcare arrangements. ${ }^{e} 1=0-19$ hours per week, $2=10-39$ hours per week, $3=40-59$ hours per week, $4=$ over $^{2} 0$ hours per week. ${ }^{\mathrm{f}}$ $0=$ responded negatively "no" to all 3 quality questions, $1=$ responded positively "yes" to 1 of 3 quality questions, $2=$ responded positively "yes" to 2 of 3 quality questions, $3=$ responded positively "yes" to all 3 quality questions. 
Family income was represented by a ratio based on what percentage of the family's income was spent on necessities such as food, clothing and shelter. The low income ratio (LICO) (Statistics Canada, 2006a) values in this study were grouped so that values below one were considered very low income, values between 1.0-1.9 were considered low income, values between 2.0-2.9 were considered medium income, and values above three were considered high income. On average, preschoolers in this study came from families in the low income ratio level $(M=1.523, S D=1.012)$. See Table 4 for descriptive statistics.

For the purposes of this study it was not particularly important if the child resided in a household with two biological parents or in a household with two parents where both were not biological parents, for example one parent is biological and the other is a step parent, or both parents are foster parents. Therefore a child was coded as living in a household with two parents if the PMK identified that they had a spouse that resided with them in the house. Otherwise, if the PMK acknowledged that there was no spouse in the household with them that child was coded as living in a single parent household. Approximately $13 \%$ of the preschoolers in this study resided in a single parent household.

The number of childcare arrangements ranged between 1 and 4 or more $(M=1.13, S D=$ 0.399). The number of hours per week in childcare (quantity) was grouped; 0-19 hours, 20-39 hours, 40-59 hours and 60 or more hours. Slightly more children attended 0-19 hours per week of childcare than 20-39 hours per week of childcare (36.4 and 35.5 respectively). The average age of entry to childcare was less than a year old $(M=0.83, S D=.810)$. The quality score reflected a cumulative total of all positive responses on the three questions; responding negatively to all questions resulted in a quality score of zero. On average children were in childcare that was moderately high in quality $(M=1.704, S D=0.682)$. See Table 4 for descriptive statistics. 
Table 5

Chi-square analysis: Crosstab percentages for all health status groups

\begin{tabular}{|c|c|c|c|c|c|c|}
\hline & NDD & EXTBEH & BOTH & HEALTHY & $\mathrm{NCH}$ & Total \% \\
\hline $\begin{array}{l}\text { Gender of Child - } \\
\text { Female }\end{array}$ & $64.8 \%$ & $56.5 \%$ & $75.0 \%$ & $49.6 \%$ & $53.8 \%$ & $51.2 \%$ \\
\hline $\begin{array}{c}\text { Gender of PMK - } \\
\text { Female }\end{array}$ & $90.0 \%$ & $87.4 \%$ & $97.2 \%$ & $91.3 \%$ & $94.9 \%$ & $91.5 \%$ \\
\hline $\begin{array}{c}\text { Single parent - } \\
\text { yes }\end{array}$ & $8.1 \%$ & $17.4 \%$ & $9.3 \%$ & $13.0 \%$ & $15.6 \%$ & $13.5 \%$ \\
\hline PMK work -yes & $76.9 \%$ & $71.7 \%$ & $58.1 \%$ & $70.0 \%$ & $69.3 \%$ & $70.1 \%$ \\
\hline $\begin{array}{c}\text { Use childcare - } \\
\text { yes }\end{array}$ & $58.8 \%$ & $56.7 \%$ & $51.9 \%$ & $49.9 \%$ & $56.7 \%$ & $51.5 \%$ \\
\hline Type of childcare: & & & & & & \\
\hline Else's home & $23.3 \%$ & $15.7 \%$ & $14.2 \%$ & $17.9 \%$ & $20.7 \%$ & $18.2 \%$ \\
\hline Own home & $9.0 \%$ & $11.1 \%$ & $14.2 \%$ & $8.8 \%$ & $8.8 \%$ & $9.0 \%$ \\
\hline Centre & $16.7 \%$ & $26.6 \%$ & $22.6 \%$ & $21.5 \%$ & $24.4 \%$ & $22.1 \%$ \\
\hline Other & $11.0 \%$ & $3.5 \%$ & $0.9 \%$ & $2.1 \%$ & $3.3 \%$ & $2.5 \%$ \\
\hline No childcare & $40.0 \%$ & $43.1 \%$ & $48.1 \%$ & $49.7 \%$ & $42.7 \%$ & $48.1 \%$ \\
\hline
\end{tabular}

Childcare was grouped into five types of childcare; care in someone else's home by a relative or non-relative, care in the child's own home by a relative or non-relative, care in a preschool/centre, other care (including before and after school care), and no childcare. Almost half of the preschoolers (48.1\%) aged 0-5 did not attend childcare. Of the children that did attend childcare, the most common type of childcare attended was centre based/pre-school care. 
Descriptive data for the continuous variables (age of child, PMK education, hours worked by PMK, LICO, number of siblings in the household, age of entry to childcare, quantity of childcare, quality of childcare, and number of childcare arrangements) are displayed per health status group in Table 4. Tables 6-10 provide descriptive statistics as well as outline the significant differences discussed below.

\section{Objective 1: Differences Between Children With and Without EOD}

The child, family, and childcare characteristics were compared between children in the five different health status groups (NDD, EXTBEH, BOTH, NCH and HEALTHY). Results for the child, family and childcare characteristics are provided below. Simes correction (Simes, 1986) was used to control for multiple comparisons resulting in a per comparison significance level of $\alpha=.0275$ (family wise $\alpha=.05$ ) for the ANOVA's and a per comparison significance level of $\alpha=.03$ (family wise $\alpha=.05$ ) for Chi- square tests. For all significant ANOVA results, GamesHowell post-hoc tests were conducted with an assumed family wise error rate of $\alpha=.05$. Initially, ANCOVA was considered to test for significant differences between the health statuses, with the family variables acting as covariates, however, the family variables had only very weak relationships with the dependent variables therefore ANOVA was used instead. See Table 5 for Chi-square crosstabs results which report the percentages of children with a particular response per health status group. All ANOVA results are listed below in Tables 6-10 and significant differences are highlighted again in the text; in the text, we also report effect sizes estimates using the un-standardized index $r$.

Child Variables. One-way Analysis of Variance was used to test for significant differences in the age of the children in the five different health status groups. Chi-square 
analysis was used to test for differences in the gender of the children among the different health status groups.

Prediction 1.1. To determine if there was a main effect of age between the five health status groups, an ANOVA was conducted. Results indicated there was a significant difference between the groups, $F(4,11483)=254.01, p<.001$, with a medium effect $(r=.26)$. The HEALTHY group $(M=2.3,95 \%, S D=1.693)$ were significantly younger than the preschoolers who were NCH $(M=2.69, S D=5.938), p<.001$, the preschoolers with NDD $(M=$ 4.33, $S D=1.012), p<.001$, the preschoolers with $\operatorname{EXTBEH~}(M=3.65, S D=1.132), p<.001$ and the preschoolers in the BOTH group $(M=4.48, S D=.664), p<.001$. In addition, the children in the EXTBEH group were significantly younger than the children in the NDD group, $p$ $<.001$ and the children in the BOTH group, $p<.001$. See Table 4 for a list of the means and standard deviations for each health status groups. For significant differences between groups, see Tables 6-10, line 1 on each Table.

To determine if there was a difference in the gender of the children across the five health status groups a chi-square analysis was conducted. Results revealed there was a significant difference in gender, $\chi^{2}(4, N=11488)=65.621, p<.001$. Although this difference was significant, the effect was small $(r=.076)$ According to expected frequencies, males were over represented in NDD (64.8\%), EXTBEH (56.5\%), BOTH (75.0\%) and NCH (51.2\%). The females were over represented in the HEALTHY group (50.4\%), but just slightly. See Table 5 for chi-square crosstab percentages, line 1.

Family Variables. Characteristics of the family as a unit (income status, number of siblings, and family structure) and characteristics of the PMK (education, employment status, and number of hours worked) were assessed for each health status group. 
Prediction 2.1. A one-way ANOVA was conducted to determine if there were differences between health status groups on household income. A significant $F(4,10634)=$ $22.162, p<.001$, small effect $(r=.10)$, difference between groups was evident from the ANOVA. The HEALTHY group had a lower family income than the NCH group, but higher income than the children in the NDD group, however, both of these differences were not significant. The children in the BOTH group had the lowest income, followed by the children in the EXTBEH group. There were significant differences between the HEALTHY children $(M=$ $1.549, S D=1.002)$ and the EXTBEH group $(M=1.295, S D=1.058), p<.001$ and between the HEALTHY and the BOTH groups $(M=0.852, S D=.879), p<.001$ with the HEALTY children. In addition, there were significant differences between children in the BOTH group and children in the NDD group $(M=1.450, S D=.926), p<.001$ and children in the EXTBEH group, $p<.001$. See Table 4 for a list of the means and standard deviations for each health status groups. For significant differences between groups, see Tables 6-10, line 6 on each Table.

Prediction 2.2. A chi-square was used to determine if there was a difference in the parent status among children with EOD and children who were HEALTHY or NCH. The results showed a significant difference $\chi^{2}(4, N=11430)=25.756, p<.001$, although there was a small effect $(r=.047)$. Within the NDD group there were fewer single parents than expected, while the EXTBEH group had more single parents than expected. The number of single parents in BOTH and HEALTHY groups was very close to as expected, although there were fewer single parents than expected. In addition, although very close to expected, the $\mathrm{NCH}$ group had more single parents than expected. See Table 5 for chi-square crosstab percentages, line 3.

Prediction 2.3. An ANOVA was conducted to determine if there was a main effect of the number of siblings currently residing in the household. Results indicated a 
significant difference in the number of siblings currently residing in the household between health status groups, $F(4,11483)=14.9, p<.001$. Although this result was significant it had a small effect $(r=.08)$. Children in the NCH group had the fewest number of siblings, closely followed by HEALTHY children. The mean number of siblings for children in the NDD group and children in the EXTBEH group were the same $(M=1.27, S D=.999), p=.008$ and $(M=$ $1.27, S D=.933), p<.001$, both being significantly different from the HEALTHY children $(M=$ $1.06, S D=.996)$. See Table 4 for a list of the means and standard deviations for each health status groups. For significant differences between groups, see Tables 6-10, line 4 on each Table.

Prediction 2.4. A chi-square was conducted to determine if there was a difference in the working status (work or not work) of parents in the different health status groups. Results confirmed that there was a significant difference $\chi^{2}(4, \mathrm{~N}=11218)=13.941, p=.007$, although the effect was small $(r=.035)$. The percentage of parents who worked was quite large and there were more parents than expected who worked in the NDD group (76.9\%) and EXTBEH group (71.7\%), although the EXTBEH group was very close to expected. In the remaining three groups, the number of parents that worked were under represented; BOTH (58.1\%), HEALTHY (70\%) and $\mathrm{NCH}(69.3 \%)$, although again all of these groups were quite close to expected values. See Table 5 for chi-square crosstab percentages, line 4.

Results from further investigation conducted by ANOVA revealed that there was no significant difference between the health status groups in regards to the number of hours per week the PMK worked $F(4,7852)=1.868, p=.113$. See Table 4 for a list of the means and standard deviations for each health status groups. For significant differences between groups, see Tables 6-10, line 5 on each Table. 
Prediction 2.5. In order to determine if there was a significant difference in the PMK level of education, an ANOVA was conducted. Results confirmed a significant difference between groups, $F(4,11365)=13.169, p<.001$, however, the effect was small $(r=.07)$. There were significant differences between the preschoolers in the HEALTHY group $(M=3.29, S D=$ $1.040)$ and preschoolers in the BOTH $(M=2.79, S D=1.189), p<.001$, and NCH $(M=3.43, S D$ $=.986), p<.001$ groups. Also, the PMK level of education was significantly different between children in the BOTH group and children in the NDD group $(M=3.31, S D=1.018), p=.001$, as well as children in the BOTH group and children in the EXTBEH group $(M=3.23, S D=1.108)$, $p=.003$. See Table 4 for a list of the means and standard deviations for each health status groups. For significant differences between groups, see Tables 6-10, line 3 on each Table.

Childcare Variables. Several childcare characteristics were examined to determine if there was a difference among the health status groups. A chi-square analysis was conducted to determine if there were differences in the rates of childcare use as well as the type of childcare used. In addition, ANOVA was used for the quantity of childcare use, number of childcare arrangements, age of entry into childcare, and quality of childcare.

Prediction 3.1. Whether or not children used childcare differed significantly $\chi^{2}(4$, $N=11488)=38.986, p<.001$, although this was a small effect $(r=.06)$. Further investigation identified that more children than expected used childcare from the NDD (58.8\%), EXTBEH (56.7\%), BOTH (51.9\%), and $\mathrm{NCH}(56.7 \%)$ groups, although the Both group was very close to expected, while HEALTHY (49.9\%) children used childcare less often then what would be expected. See Table 5 for chi-square crosstab percentages, line 5.

Prediction 3.2. There was a significant difference in the type of childcare used for the different health status groups $\chi^{2}(16, N=11386)=141.784, p<.001$, although the effect was 
small $(r=.11)$. Within the NDD group, there were less children than expected that attended no childcare (40\%), of those that did attend childcare there were fewer than expected that attended centre based care (16.7\%), and more than expected that attended other types of childcare (11\%), care in their own home $(9.0 \%)$, and care in someone else's home $(23.3 \%)$. For children in the EXTBEH group, there were more children than expected that attended centre based care (26.6\%), care in their own home (11.1\%), and other types of childcare $(3.5 \%)$. There were fewer children than expected with EXTBEH that attended childcare in someone else's home (15.7\%), or did not attend childcare $(43.1 \%)$. Children in the BOTH group attended childcare in their own home (14.2\%) slightly more than expected, while they attended care in someone else's home (14.2\%) slightly less than expected. The childcare attendance at centre based care $(22.6 \%)$ and no childcare $(48.1 \%)$ were very close to expected levels. Children who were HEALTHY attended centre based care (21.5\%) and no childcare (49.7\%) more than expected and they attended care in someone else's home (17.9\%), care in their own home (8.8\%), and other types of childcare $(2.1 \%)$ less than expected. Finally children who were $\mathrm{NCH}$ attended childcare in someone else's home (20.7\%), centre based care (24.4\%) and other types of childcare (3.3\%) more than expected but had less children than expected that did not attend childcare $(42.7 \%)$ or had care in their own home (8.8\%). See Table 5 for chi-square crosstab percentages, lines 6-9.

Prediction 3.3. Although there was a significant difference in the quantity $F(4,5$ $884)=11.634, p<.001$ of childcare used between the health status groups, the effect of this difference was small $(r=.09)$. Healthy $(M=2.05, S D=.800)$ children used the most childcare while children with NDD $(M=1.62, S D=.728)$ used the least amount of childcare, this difference was statistically significant $p<.001$. The children in the NDD group were also significantly different from the children in the EXTBEH group $(M=2.000, S D=.747), p<.001$. 
See Table 4 for a list of the means and standard deviations for each health status groups. For significant differences between groups, see Tables 6-10, line 8 on each Table.

Prediction 3.4. The number of childcare arrangements between the health status groups differed significantly, $F(4,5906)=3.124, p=.014$, although with a small effect $(r=$ .05). The only significant difference between groups did not occur between the HEALTHY children and children with EOD, rather it was between children with NDD $(M=1.06, S D=.251)$ and children who were $\mathrm{NCH}(M=1.16, S D=.452), p=.001$. See Table 4 for a list of the means and standard deviations for each health status groups. For significant differences between groups, see Tables 6-10, line 7 on each Table.

Prediction 3.5. Results from the ANOVA revealed that there was a significant difference, although just, between health status groups in regards to age of entry into childcare $F(4,3533)=2.822, p=.024$, this effect was also small $(r=.06)$. Significant differences lied between the HEALTHY children $(M=.81, S D=.788)$ and children with EXTBEH $(M=.93, S D$ $=.788), p=.044$. See Table 4 for a list of the means and standard deviations for each health status groups. For significant differences between groups, see Tables 6-10, line 9 on each Table.

Prediction 3.6. The quality of childcare also differed between the health status groups $F(4,5888)=3.302, p=.010$ but with a small effect size $(r=.05)$. Children who were HEALTHY had a significantly higher level of quality $(M=1.706, S D=.682)$ than children in the NDD group $(M=1.545, S D=.587), p=.013$. See Table 4 for a list of the means and standard deviations for each health status groups. For significant differences between groups, see Tables 6-10, line 10 on each Table. 


\section{Summary of the Differences Between Children With and Without EOD}

Several differences in child, family, and childcare characteristics were discovered between children with and without EOD. Specifically, children with EOD were older and more likely to be male, while HEALTHY children were younger and more likely to be female. In addition, children with EOD resided in bigger families (more siblings) and had lower incomes. Finally, although children with EOD attended more childcare than expected, when compared to HEALTHY children, children with EOD entered childcare later, attended fewer hours of childcare per week, had fewer different childcare arrangements, and had the lowest level of perceived quality. Unexpectedly, there were some significant differences among children with EOD. For example, children in the BOTH group had PMKs with a lower level of education and significantly lower household income levels than children in the NDD and EXTBEH groups. 
Table 6

Descriptive statistics and results of Games-Howell post hoc tests comparing the NDD to all other groups

\begin{tabular}{|c|c|c|c|c|c|c|c|c|}
\hline & & & $95 \%$ & $\% \mathrm{CI}$ & & $p$ by he & h status & \\
\hline & Mean & $\mathrm{SD}$ & Lower & Upper & EXTBEH & BOTH & $H E A L T H Y$ & $\mathrm{NCH}$ \\
\hline Age of child & 4.330 & 1.012 & 4.200 & 4.450 & $0.000 * * *$ & 0.927 & $0.000 * * *$ & $0.000 * * *$ \\
\hline Age of PMK & 34.460 & 5.631 & 33.750 & 35.160 & 0.149 & 1.000 & 0.000 & $0.047 *$ \\
\hline PMK education $^{\mathrm{a}}$ & 3.310 & 1.018 & 3.180 & 3.430 & 0.882 & $0.001 * * *$ & 1.000 & 0.363 \\
\hline Number of siblings & 1.270 & 0.999 & 1.150 & 1.400 & 1.000 & 0.877 & 0.008 & $0.004 * *$ \\
\hline Hours worked ${ }^{b}$ & 3.870 & 1.184 & 3.700 & 4.040 & 0.103 & 0.597 & 0.398 & 0.095 \\
\hline $\operatorname{LICO}^{c}$ & 1.450 & 0.926 & 1.323 & 1.571 & 0.210 & $0.000 * * *$ & 0.512 & 0.542 \\
\hline Number of arrangements ${ }^{d}$ & 1.060 & 0.251 & 1.020 & 1.100 & 0.073 & 0.651 & 0.056 & $0.001 * *$ \\
\hline Quantity $^{\mathrm{e}}$ & 1.620 & 0.728 & 1.500 & 1.740 & $0.000 * * *$ & 0.395 & 0.000 & $0.000 * * *$ \\
\hline Age of entry & 0.940 & 1.067 & 0.770 & 1.110 & 1.000 & 1.000 & 0.601 & 0.675 \\
\hline Quality $^{\mathrm{f}}$ & 1.545 & 0.587 & 1.449 & 1.641 & 0.291 & 0.352 & $0.013 *$ & $0.003 * *$ \\
\hline
\end{tabular}

${ }^{*} p<.05 * * p<.01 * * * p<.001$

Note: ${ }^{\mathbf{a}} 1=$ less than secondary education, $2=$ secondary graduate, $3=$ some post-secondary, $4=$ =post secondary graduate, $5=$ other. ${ }^{\mathbf{b}} 1=$ less than 10 hours, 2=between 10-19 hours, $3=$ between 20-29 hours, $4=$ between 30-39 hours, $5=$ over 50 hours. ${ }^{\mathbf{c}} 0-0.9=$ very low income, $1.0-1.9=$ low income, 2.0-2.9=moderate income, 3 or more $=$ high income; ${ }^{\mathrm{d}} 1=1$ childcare arrangement, $2=2$ childcare arrangements, $3=3$ childcare arrangements, $4=$ more than 4 childcare arrangements. ${ }^{\mathrm{e}} 1=0-19$ hours per week, $2=10-39$ hours per week, $3=40-59$ hours per week, $4=$ over 60 hours per week. ${ }^{\mathrm{f}}$ $0=$ responded negatively "no" to all 3 quality questions, $1=$ responded positively "yes" to 1 of 3 quality questions, $2=$ responded positively "yes" to 2 of 3 quality questions, $3=$ responded positively "yes" to all 3 quality questions. 
Table 7

Descriptive statistics and results of Games-Howell post hoc tests comparing the EXTBEH to all other groups.

\begin{tabular}{|c|c|c|c|c|c|c|c|c|}
\hline & \multirow[b]{2}{*}{ Mean } & \multicolumn{3}{|c|}{$95 \% \mathrm{CI}$} & \multicolumn{4}{|c|}{ p by health status } \\
\hline & & $\mathrm{SD} I$ & Lower & Upper & $N D D$ & BOTH & HEALTHY & $\mathrm{NCH}$ \\
\hline Age of child & 3.650 & 1.132 & 3.570 & 3.720 & $0.000 * * *$ & $0.000 * * *$ & $0.000 * * *$ & $0.000 * * *$ \\
\hline Age of PMK & 33.49 & 6.237 & 33.06 & 33.93 & 0.149 & 0.521 & 0.012 & 0.994 \\
\hline PMK education $^{\mathrm{a}}$ & 3.230 & 1.108 & 3.160 & 3.310 & 0.882 & $0.003 * *$ & 0.589 & $0.000 * * *$ \\
\hline Number of siblings & 1.270 & 0.933 & 1.210 & 1.340 & 1.000 & 0.823 & $0.000 * * *$ & $0.000 * * *$ \\
\hline Hours worked ${ }^{b}$ & 4.120 & 1.294 & 4.020 & 4.230 & 0.103 & 1.000 & 0.437 & 0.270 \\
\hline $\mathrm{LICO}^{\mathrm{c}}$ & 1.295 & 1.058 & 1.218 & 1.372 & 0.210 & $0.000 * * *$ & $0.000 * * *$ & $0.000 * * *$ \\
\hline Number of arrangements ${ }^{d}$ & 1.140 & 0.411 & 1.100 & 1.170 & 0.073 & 0.999 & 0.945 & 0.801 \\
\hline Quantity $^{\mathrm{e}}$ & 2.000 & 0.747 & 1.930 & 2.070 & $0.000 * * *$ & 0.668 & 0.634 & 0.847 \\
\hline Age of entry & 0.930 & 0.788 & 0.850 & 1.010 & 1.000 & 1.000 & 0.044 & 0.196 \\
\hline Quality $^{\mathrm{f}}$ & 1.656 & 0.629 & 1.598 & 1.714 & 0.291 & 0.914 & 0.515 & 0.157 \\
\hline
\end{tabular}

Note: ${ }^{a} 1=$ less than secondary education, $2=$ secondary graduate, $3=$ some post-secondary, $4=$ post secondary graduate, $5=$ other. ${ }^{\mathbf{b}} 1=$ less than 10 hours, $2=$ between 10-19 hours, $3=$ =between $20-29$ hours, $4=$ between $30-39$ hours, $5=$ over 50 hours. ${ }^{\mathrm{c}} 0-0.9=$ very low income, $1.0-1.9=$ low income, 2.0-2.9=moderate income, 3 or more=high income; ${ }^{\mathrm{d}} 1=1$ childcare arrangement, $2=2$ childcare arrangements, $3=3$ childcare arrangements, $4=$ more than 4 childcare arrangements. ${ }^{\mathbf{e}} 1=0-19$ hours per week, $2=10-39$ hours per week, $3=40-59$ hours per week, $4=$ over 60 hours per week. ${ }^{\mathrm{f}}$ $0=$ responded negatively "no" to all 3 quality questions, $1=$ responded positively "yes" to 1 of 3 quality questions, $2=$ responded positively "yes" to 2 of 3 quality questions, $3=$ responded positively "yes" to all 3 quality questions. 
Table 8

Descriptive statistics and results of Games-Howell post hoc tests comparing the BOTH to all other groups

\begin{tabular}{lccccccccc}
\hline & & \multicolumn{4}{c}{$95 \%$ CI } & \multicolumn{3}{c}{$p$ by health status } \\
& Mean & SD & Lower & Upper & NDD & EXTBEH & HEALTHY & NCH \\
\hline Age of child & 4.480 & 0.664 & 4.350 & 4.610 & 0.927 & $0.000 * * *$ & $0.000 * * *$ & $0.000 * * *$ \\
Age of PMK & 34.39 & 5.469 & 33.35 & 35.43 & 1.000 & 0.521 & $0.021 *$ & 0.358 \\
PMK education & a & 2.790 & 1.189 & 2.560 & 3.020 & $0.001 * * *$ & $0.003 * *$ & $0.000 * * *$ & $0.000 * * *$ \\
Number of siblings & 1.380 & 0.916 & 1.200 & 1.550 & 0.877 & 0.823 & $0.004 * *$ & $0.002 * *$ \\
Hours worked $^{\mathrm{b}}$ & 4.100 & 1.003 & 3.840 & 4.350 & 0.597 & 1.000 & 0.983 & 0.134 \\
LICO $^{\mathrm{c}}$ & 0.852 & 0.879 & 0.676 & 1.028 & $0.000 * * *$ & $0.000 * * *$ & $0.000 * * *$ & $0.000 * * *$ \\
Number of arrangements $^{\mathrm{d}}$ & 1.150 & 0.481 & 1.030 & 1.280 & 0.651 & 0.999 & 0.985 & 1.000 \\
Quantity $^{\mathrm{e}}$ & 1.850 & 0.833 & 1.620 & 2.070 & 0.395 & 0.668 & 0.352 & 0.406 \\
Age of entry $_{\text {Quality }}^{\mathrm{f}}$ & 0.920 & 0.849 & 0.730 & 1.120 & 1.000 & 1.000 & 0.781 & 0.825 \\
\hline
\end{tabular}

${ }^{*} p<.05 * * p<.01 \quad * * * p<.001$

Note: ${ }^{a} 1=$ less than secondary education, $2=$ secondary graduate, $3=$ some post-secondary, $4=$ post secondary graduate, $5=$ other. ${ }^{b} 1=$ less than 10 hours, $2=$ between 10-19 hours, $3=$ between $20-29$ hours, $4=$ between $30-39$ hours, $5=$ over 50 hours. ${ }^{\mathrm{c}} 0-0.9=$ very low income, $1.0-1.9=$ low income, 2.0-2.9=moderate income, 3 or more $=$ high income; ${ }^{\mathrm{d}} 1=1$ childcare arrangement, $2=2$ childcare arrangements, $3=3$ childcare arrangements,

$4=$ more than 4 childcare arrangements. ${ }^{\mathbf{e}} 1=0$-19 hours per week, $2=10-39$ hours per week, $3=40-59$ hours per week, $4=$ over $^{2} 60$ hours per week. ${ }^{\mathrm{f}}$ $0=$ responded negatively "no" to all 3 quality questions, $1=$ responded positively "yes" to 1 of 3 quality questions, $2=$ responded positively "yes" to 2 of 3 quality questions, $3=$ responded positively "yes" to all 3 quality questions. 
Table 9

Descriptive statistics and results of Games-Howell post hoc tests comparing the HEALTHY to all other groups

\begin{tabular}{|c|c|c|c|c|c|c|c|c|}
\hline & \multirow[b]{2}{*}{ Mean } & \multicolumn{3}{|c|}{$95 \% \mathrm{CI}$} & \multicolumn{4}{|c|}{$p$ by health status } \\
\hline & & $\mathrm{SD}$ & Lower & Upper & NDD & EXTBEH & BOTH & $\mathrm{NCH}$ \\
\hline Age of child & 2.300 & 1.693 & 2.260 & 2.330 & $0.000 * * *$ & $0.000 * * *$ & $0.000 * * *$ & $0.000 * * *$ \\
\hline Age of PMK & 32.75 & 5.948 & 32.63 & 32.88 & $0.000 * * *$ & $0.012 *$ & $0.021 *$ & $0.002 * *$ \\
\hline PMK education $^{\mathrm{a}}$ & 3.290 & 1.040 & 3.270 & 3.320 & 1.000 & 0.589 & $0.000 * * *$ & $0.000 * * *$ \\
\hline Number of siblings & 1.060 & 0.996 & 1.040 & 1.080 & $0.008 * *$ & $0.000 * * *$ & $0.004 * *$ & 0.893 \\
\hline Hours worked ${ }^{b}$ & 4.030 & 1.233 & 3.990 & 4.060 & 0.398 & 0.437 & 0.983 & 0.905 \\
\hline $\mathrm{LICO}^{\mathrm{c}}$ & 1.549 & 1.002 & 1.527 & 1.570 & 0.512 & $0.000 * * *$ & $0.000 * * *$ & 1.000 \\
\hline Number of arrangements ${ }^{d}$ & 1.120 & 0.389 & 1.110 & 1.130 & 0.056 & 0.945 & 0.985 & 0.078 \\
\hline Quantity $^{\mathrm{e}}$ & 2.050 & 0.800 & 2.030 & 2.080 & $0.000 * * *$ & 0.634 & 0.352 & 1.000 \\
\hline Age of entry & 0.810 & 0.788 & 0.780 & 0.840 & 0.601 & 0.044 & 0.761 & 1.000 \\
\hline Quality $^{\mathrm{f}}$ & 1.706 & 0.682 & 1.685 & 1.726 & $0.013 *$ & 0.515 & 0.996 & 0.612 \\
\hline
\end{tabular}

$* p<.05 * * p<.01 * * * p<.001$

Note: ${ }^{a} 1=$ less than secondary education, $2=$ secondary graduate, $3=$ some post-secondary, $4=$ post secondary graduate, $5=$ other. ${ }^{b} 1=$ less than 10 hours, 2=between 10-19 hours, $3=$ between $20-29$ hours, $4=$ between 30-39 hours, $5=$ over 50 hours. ${ }^{\mathrm{c}} 0-0.9=$ very low income, 1.0-1.9=low income, 2.0-2.9=moderate income, 3 or more $=$ high income; ${ }^{\mathrm{d}} 1=1$ childcare arrangement, $2=2$ childcare arrangements, $3=3$ childcare arrangements, $4=$ more than 4 childcare arrangements. ${ }^{\mathrm{e}} 1=0$-19 hours per week, $2=10-39$ hours per week, $3=40-59$ hours per week, $4=$ over 60 hours per week. ${ }^{\mathrm{f}}$ $0=$ responded negatively "no" to all 3 quality questions, $1=$ responded positively "yes" to 1 of 3 quality questions, $2=$ responded positively "yes" to 2 of 3 quality questions, $3=$ responded positively "yes" to all 3 quality questions. 
Table 10

Descriptive statistics and results of Games-Howell post hoc tests comparing the NCH to all other groups

\begin{tabular}{|c|c|c|c|c|c|c|c|c|}
\hline & \multirow[b]{2}{*}{ Mean } & \multirow[b]{2}{*}{$\mathrm{SD}$} & \multicolumn{2}{|c|}{$95 \% \mathrm{CI}$} & \multicolumn{4}{|c|}{$p$ by health status } \\
\hline & & & Lower & Upper & NDD & EXTBEH & BOTH & HEALTHY \\
\hline Age of child & 2.690 & 1.665 & 2.610 & 2.780 & $0.000 * * *$ & $0.000 * * *$ & $0.000 * * *$ & $0.000 * * *$ \\
\hline Age of PMK & 33.38 & 5.938 & 33.08 & 33.68 & $0.047 * *$ & 0.994 & 0.358 & $0.002 * *$ \\
\hline PMK education $^{\mathrm{a}}$ & 3.430 & 0.986 & 3.380 & 3.480 & 0.363 & $0.000 * * *$ & $0.000 * * *$ & $0.000 * * *$ \\
\hline Number of siblings & 1.030 & 0.876 & 0.990 & 1.080 & $0.004 * *$ & $0.000 * * *$ & $0.002 * *$ & 0.893 \\
\hline Hours worked $^{b}$ & 3.990 & 1.206 & 3.920 & 4.060 & 0.717 & 0.270 & 0.933 & 0.905 \\
\hline $\mathrm{LICO}^{\mathrm{c}}$ & 1.553 & 1.040 & 1.499 & 1.608 & 0.542 & $0.000 * * *$ & $0.000 * * *$ & 1.000 \\
\hline Number of arrangements ${ }^{d}$ & 1.160 & 0.452 & 1.130 & 1.190 & $0.001 * *$ & 0.801 & 1.000 & 0.076 \\
\hline Quantity $^{\mathrm{e}}$ & 2.050 & 0.789 & 1.990 & 2.100 & $0.000 * * *$ & 0.847 & 0.406 & 1.000 \\
\hline Age of entry & 0.810 & 0.838 & 0.740 & 0.890 & 0.675 & 0.196 & 0.825 & 1.000 \\
\hline Quality $^{\mathrm{f}}$ & 1.744 & 0.025 & 1.695 & 1.793 & $0.003 * *$ & 0.157 & 1.000 & 0.612 \\
\hline
\end{tabular}

Note: ${ }^{\mathbf{a}} 1=$ less than secondary education, $2=$ secondary graduate, $3=$ some post-secondary, $4=$ post secondary graduate, $5=$ other. ${ }^{\mathbf{b}} 1=$ less than 10 hours, $2=$ between 10-19 hours, $3=$ between $20-29$ hours, $4=$ between $30-39$ hours, $5=$ over 50 hours. ${ }^{\mathbf{c}} 0-0.9=$ very low income, $1.0-1.9=$ low income, 2.0-2.9=moderate income, 3 or more $=$ high income; ${ }^{\mathrm{d}} 1=1$ childcare arrangement, $2=2$ childcare arrangements, $3=3$ childcare arrangements, $4=$ more than 4 childcare arrangements. ${ }^{\mathrm{e}} 1=0$-19 hours per week, $2=10-39$ hours per week, $3=40-59$ hours per week, $4=$ over 60 hours per week. ${ }^{\mathrm{f}}$ $0=$ responded negatively "no" to all 3 quality questions, $1=$ responded positively "yes" to 1 of 3 quality questions, $2=$ responded positively "yes" to 2 of 3 quality questions, $3=$ responded positively "yes" to all 3 quality questions. 


\section{Objective 2: The Relationships Between Family and Childcare Variables and the Outcomes}

Several regressions were performed to determine the relationship between the family variables and child developmental outcomes in language and cognitive domains (evaluated by the PPVT and Who am I? respectively), for preschoolers, aged four and five, who were HEALTHY and children with NDD, EXTBEH, and NCH. As mentioned previously, there were not enough preschoolers aged four and five in the BOTH group as such, the children in this group were absorbed in the NDD group.

A separate regression was conducted for each health status group and for each outcome variable. Results will be discussed per health status group for each outcome variable separately. An Income X Quality interaction was originally added to the regression model as some research supports this interaction (Votruba-Drzal et al., 2004; Watamura et al., 2011). However, in this research the interaction did not significantly contribute anything to the model and so analysis was conducted again after removing the interaction. The accompanying results below will discuss the full model (family and childcare variables in the same model) for each outcome. In addition to the model summary statistics reported, the model parameters, including the $\beta, t$, and the part and partial correlations ( $s r$ and $p r$ respectively) will be addressed. However the regression effects will, be evaluated in terms of the effect size or practical significance and not statistical significance, thus, there will be no comparisons (tests of significance) between the beta coefficents of the separate regressions (slope analysis). For all regression results refer to the appendix Tables A1.1 through A1.2.

Healthy. When childcare characteristics (blocked) were entered into the same model as family variables (blocked) both family variables and childcare variables accounted for a significant proportion of the variance in the PPVT scores, $F_{\text {famlly and chldcare }}(13,730)=5.120, p<$ 
.001 . When considered on its own, the family variables accounted for a significant amount of the variance in PPVT scores, $F_{\text {change }}(6,737)=8.364, p<.001$ and when childcare variables were added the amount of variance accounted for was still significant, $F_{\text {change }}(7,730)=2.254, p=$ .028 . Specifically, when only family variables were in the model $6 \%\left(R_{\text {change }}^{2}=.064\right)$ of the variance in PPVT scores was accounted for, by adding childcare to the model an additional $2 \%$ $\left(R_{\text {change }}^{2}=.02\right)$ of the variance in PPVT could be accounted for. When taking a closer look at the model parameters it was seen that hours worked, PMK education, income, number of siblings, age of the child and hours in childcare predicted PPVT scores, as they all had significant slopes. However, the number of siblings $(\beta=-.144, t(730)=-3.787, p<.001, s r=-.134)$ and quantity of childcare $(\beta=-.135, t(730)=-3.513, p<.001, s r=-.124)$ appear to be the best predictors as they both had significant slopes and contributed the most unique variance (between $1.5 \%$ and $1.8 \%$ ) to the PPVT scores. Results indicated that as the number of siblings and quantity of childcare increased, the scores on the PPVT decreased. Refer to the appendix Tables A1.1.

The same family and childcare variables had a different relationship with the Who am I?, although still significant $F(13,730)=5.50, p<.001$. When in the model alone, the family variables accounted for a significant amount of variance in the Who am $\mathrm{I} ?,\left(R_{\text {change }}^{2}=.083\right.$, $\left.F_{\text {change }}(6,737)=11.081, p<.001\right)$, however, the childcare variables did not significantly contribute to the amount of variance accounted for $\left(R^{2}\right.$ change $=.006, F_{\text {change }}(7,730)=.739, p=$ $.639)$. Finally, hours worked $(\beta=-.081, t(730)=2.16, p=.03, s r=.076)$, parent marital status $(\beta$ $=-.097, t(730)=-2.706, p=.007, s r=-.096)$, income $(\beta=.162, t(730)=4.298, p<.001, s r=$ $.152)$ and age of the child $(\beta=.192, t(730)=5.039, p<.001, s r=.178)$ all had significant slopes however, income and age of the child contributed the most unique variance (approximately $2 \%$ 
and $3 \%$ respectively). In both income and age of the child, the Who am I? scores increased as income and age of the child increased. Refer to the appendix Tables A1.2.

NCH. Family and childcare characteristics accounted for a significant amount of variance in the PPVT, $F(13,187)=2.419, p=.005$. When only family variables were in the model approximately $10 \%$ of the variance was accounted for $\left(R_{\text {change }}^{2}=.099, F_{\text {change }}(6,194)=\right.$ $3.561, p=.002$ ). By adding childcare variables to the model an additional approximately $5 \%$ $\left(R_{\text {change }}^{2}=.045\right)$ of the variance was accounted for, however, this difference was not significant, $F(7,187)=1.397, p=.209$. Further examination of the model parameters identified that of the family variables, only parent marital status had a slope significantly different from zero $(\beta=$ $.210, t(187)=2.909, p=.004)$ and it accounted for approximately $4 \%$ of unique variance $\left(s r^{2}=\right.$ .039). Refer to the appendix Tables A1.1.

When family and childcare characteristics were entered in the same model, there was a significant amount of variance accounted for, $F(13,179)=5.099, p<.001$ in the scores for the Who am I?. The family variables had a similar relationship to the Who am I scores as with the PPVT scores. When only family variables were in the model approximately $22 \%$ of the variance was accounted for $\left(R_{\text {change }}^{2}=.221, F_{\text {change }}(6,185)=8.809, p<.001\right)$. By adding childcare variables to the model an additional approximately $5 \%\left(R_{\text {change }}^{2}=.049\right)$ of the variance was accounted for, however, this difference was not significant, $F_{\text {change }}(7,178)=1.715, p=.108$. All of the family variables, with the exception of the number of siblings currently residing in the household, had significant slopes $\left(\beta_{\text {hours worked }}=.279, t(179)=3.929, p<.001, s r=.251 ; \beta_{\text {PMK }}\right.$ education $=.191, t(179)=2.824, p=.005, s r=.180 ; \beta_{\text {Income }}=-.162, t(179)=-2.359, p=.019, s r=$ $-.151 ; \beta_{\text {parent martal status }}=.156, t(179)=2.271, p=.024, s r=.145 ; \beta_{\text {age of chlld }}=.201, t(179)=2.671$, 
$p=.008, s r=.171)$, and accounted for between $2 \%$ and $6 \%$ of the unique variance. Refer to the appendix Tables A1.2.

NDD. For children with NDD, the family and childcare variables did not account for a significant amount of variance in the PPVT scores, $F(13,78)=1.866, p=.096$. Refer to the appendix Tables A1.1. However, the family and childcare variables accounted for a significant amount of variance in the Who am I? scores, $F(13,79)=2.866, p=.002$. Family variables alone accounted for a significant amount of the variance in Who am I? scores $\left(R_{\text {change }}^{2}=.137, F_{\text {change }}(6\right.$, $86)=2.286, p=.043)$. When the childcare characteristics were added an additional $18 \%$ $\left(R^{2}\right.$ change $\left.=.183\right)$ of the variance in the Who am I? scores could be accounted for, this was significant, $F_{\text {change }}(7,79)=3.040, p=.007$. When taking a closer look at the model parameters it was seen that age of the child $(\beta=.279, t(79)=2.135, p=.036, s r=.196)$, quality $(\beta=-.271$, $t(79)=-2.177, p=.032, s r=-.202)$, and type of childcare, specifically care is someone else's home $(\beta=-.335, t(79)=-2.314, p=.023, s r=-.214)$ and care in the child's own home $(\beta=-$ $.354, t(79)=-2.922, p=.005, s r=-.271)$ were decent predictors of Who am I? scores, as they all had significant slopes and contributed more than approximately $4 \%$ of the unique variance in the Who am I? scores. Refer to the appendix Tables A1.2.

EXTBEH. In the regression model with both the family variables and childcare characteristics entered, there was a significant proportion of variance in the PPVT scores accounted for, $F(13,120)=4.164, p<.001$. When family variables were in the regression model on their own a significant amount of the variance in PPVT was accounted for $\left(R_{\text {change }}^{2}=.291\right.$, $\left.F_{\text {change }}(6,127)=8.705, p<.001\right)$. When the childcare characteristics were added an additional approximately $2 \%\left(R_{\text {change }}^{2}=.019\right)$ of the variance in the PPVT scores could be accounted for however, this was not significant, $F_{\text {change }(7,120)}=.484, \mathrm{p}=.845$. Model parameters suggest 
income $(\beta=.308, t(120)=3.331, p=.001, s r=.251)$, number of siblings $(\beta=-.189, t(120)=-$ $2.284, p=.024, s r=-.173)$ and age of the child $(\beta=.184, t(120)=2.184, p=.031, s r=.165)$ were the strongest predictors of PPVT scores. Refer to the appendix Tables A1.1.

Again, when the family and childcare characteristics were in the same regression model there was a significant amount of variance in the Who am I? scores accounted for, $F(13,117)=$ $2.689, p=.002$. However, when just the family variables were in the regression model, the amount of variance accounted for in the Who am I? scores was not significant $\left(R_{\text {change }}^{2}=.094\right.$, $\left.F_{\text {change }}(6,124)=2.142, p=.053\right)$, but when the childcare variables were added an additional approximately $14 \%\left(R_{\text {change }}^{2}=.136\right)$, this was significant, $\left.F_{\text {change }}(7,117)=2.956, p=.007\right)$. A closer look at the model parameters identified that quality of childcare $(\beta=-.265, t(117)=-$ $2.497, p=.014, s r=-.202)$ and type of childcare, specifically care in the child's own home $(\beta=$ $.245, t(117)=-2.071, p=.041, s r=-.168)$ and other types of childcare $(\beta=-.261, t(117)=$ $2.836, p=.005, s r=-.230$ ) were the best predictors of Who am I? scores for children with EXTBEH. Refer to the appendix Tables A1.2.

\section{Summary of the Influence of Family and Childcare Variables on Language and Cognitive}

\section{Outcomes for Children With and Without EOD}

In both children with NDD and children with EXTBEH, childcare characteristics predicted scores on the Who am I?. This showed that at least for cognitive aspects, these characteristics would influence the development of a child with EOD. In HEALTHY children, as expected, the language and cognitive outcomes where influenced more by family factors than childcare factors. 


\section{Discussion}

The rates of childcare have increased in recent years (Beach et al., 2009; Smith, 2002) and although there is an abundance of research regarding the effects of childcare, a majority of this research has involved only typically developing children. Furthermore, the results of the existing research are ambiguous; some studies suggest detrimental effects of childcare while others suggest positive effects (for summaries see Booth \& Kelly, 2002; Romano et al., 2010; Sphancer, 2006). The purpose of the current study was to use a Canadian nationally representative sample to examine the use and influence of childcare for preschool aged children with Early Observable Differences (EOD).

With the exception of the level of education of the PMK, the age of the PMK and the age of the child, there were no significant differences found between children who were HEALTHY and children who were $\mathrm{NCH}$. While the difference between the age of the children in both the HEALTHY and NCH can be accounted for by elapsed time, it is unclear why the other difference between HEALTHY and NCH children might exist. We had no theoretical rationale for predicting or explaining such differences. It may well be that chronic conditions actually determine education and parenthood timing of the PMK. However, since these differences were not in the scope of the present study, we focus our discussion on the comparison between the HEALTHY and the EOD groups, as well as the comparisons within the groups included in the EOD category.

\section{Child and Family Variables}

It was expected that there would be no variation among health status groups in regards to children's characteristics, that is, the preschooler's age and gender. However, results indicated that children who were HEALTHY were significantly younger than children who were $\mathrm{NCH}$ or 
had EOD. Of the children with EOD, the children in the EXTBEH group were the youngest, followed by children with NDD and then finally children with BOTH, who were the oldest. Research has shown that a professional diagnosis can take time, years even, and that some children are not professionally diagnosed until after starting school (Lach et al., 2009; Statistics Canada, 2006a). Therefore, it was not surprising that children with EOD were older than children who were HEALTHY. It was also anticipated that the gender of children would be consistent across health status groups. However, this was not supported by the results. It was found instead that although the gender for children who were HEALTHY was close to what was expected, HEALTHY children were more likely to be female. In contrast, children who were NCH and children with EOD were more likely to be male.

Finding childcare for any child can be a challenging task. It is even more challenging when the child has EOD (Buysse et al., 1999; Friendly \& Prentice, 2009; Kagan et al., 1999; Mulvihill et al., 2002; Rosenzweig et al., 2008). Not being able to utilize childcare creates barriers, such as decreased levels of employment (Cuskelly et al., 1998; Kagan et al., 1999; Powers, 2003; Shearn \& Todd, 2000), in the lives of the families of the children with EOD. Significant differences between health status groups were detected in regards to the working status (does the PMK work or not) of the PMK. The differences, however, were not as expected. Specifically, it was expected that PMK's of children with EOD would be less likely to be employed (Kagan et al., 1999), and those that were employed would work fewer hours (Cuskelly et al., 1998; Powers, 2003; Shearn \& Todd, 2000). However, results from this study identified that the PMK's of children with NDD and EXTBEH were employed more often than expected, suggesting that at least in part, PMK's of children with EOD did not work less often. In support of this, there was no significant difference found between health status groups on the number of 
hours the PMK worked per week. Although the number of hours the PMK worked did not differ significantly between health status groups, on average the PMK's of the children with NDD worked the least number of hours per week. In part, this lack of difference in the number of hours worked could be related to the response options available to the PMK (the response options were grouped for example, 0-10 hours, 11-20 hours etc.). It is possible that if the respondents reported the actual number of hours worked that a significant difference might have been found. Although these results were not entirely expected, previous research does suggest that parents of children with EOD often aspire to work and find employment, even if the job is below their skill set, just to provide relief from financial dependence and/or daily stressors (Shearn \& Todd, 2000).

With respects to work status, it was expected that there would be a difference in income between health status groups such that children with EOD would be more likely to live in families with lower incomes (Parish et al., 2005; Powers, 2003). Although the results suggested there was a significant difference between health status groups, the difference was not quite as expected. There was a significant difference between children who were HEALTHY and children with EXTBEH and BOTH but not between children who were HEALTHY and children with NDD. Rather children with NDD were more similar to HEALTHY and NCH children in terms of the income ratio for their family. For this study income was evaluated by an income needs ratio, meaning the value is a ratio between the families income and what percentage of that income is spent on needs such as clothing, food, housing, medical expenses etc. Lower incomes in children with EXTBEH and BOTH could possibly be related to the additional financial assistance that children with NDD might receive. Additional funding is provided to the families of children with EOD if the child has a professional diagnosis. Children with EXTBEH are not 
usually eligible for additional funding as they do not currently have a professional diagnosis (Andrew Fleck Child Care Services, 2008). In addition, even though the children with BOTH had a professional diagnosis, any financial assistance they might receive may not have been enough to offset the additional expense of having a child with multiple health concerns. Furthermore, the PMK's of children in the BOTH group were found to be employed less often than expected, likely resulting in less of an income.

The same pattern found in the age of the child was repeated for the age of the PMK, hence children who were HEALTHY had PMK's who were significantly younger than children who were $\mathrm{NCH}$ and children with EOD. The mean number of siblings for each health status group was expected to be similar yet a significant difference was found between the children who were HEALTHY and the children with EOD. Interestingly, children with EOD resided in families that had more siblings than families of children who were HEALTHY or children who were $\mathrm{NCH}$.

Prior research (Hartley et al., 2010; Wymbs et al., 2008) has suggested that parents of children with differences were more likely to be divorced. Although the results from the current study indicated that there was a significant difference in the PMK marital status, children with NDD had fewer single parents than expected and children with EXTBEH had more single parents than expected, it did not specifically address divorce per se rather whether or not the PMK had a 'spouse' living in the same household. It is entirely possible that the PMK's had previously been divorced and are currently remarried or living common-law. This study's method was not sensitive to this.

Delgado and colleagues (2007) identified that mothers who had less than 12 years of education had an increased chance of having a child with a developmental disorder. As such, it 
was expected that there would be a significant difference in the PMK education level between HEALTHY children and children with EOD. It was determined that there was a significant difference between the groups in that children with EXTBEH and BOTH had PMK's that had lower levels of education compared to children who were HEALTHY, NCH or NDD. Although children with NDD were more similar to HEALTHY children as far as the mother's education level, this might be related to the fact that mothers of children with NDD were significantly older than mothers of children who were HEALTHY. This difference in education might also account for the differences in family income.

\section{Childcare}

Differences between the characteristics of childcare were expected in all areas with the exception that the number of childcare arrangements and type of childcare would be similar across all health status groups (Booth-LaForce \& Kelly, 2004). Nevertheless, contrary to expectations there were significant differences in the number of arrangements. Specifically, the only significant difference was between children with NDD and children who were NCH; children who were $\mathrm{NCH}$ had the highest number of childcare arrangements and children with NDD had the fewest number of childcare arrangements.

It was anticipated that children with EOD would be less likely to attend childcare (Lero et al., 2000), at odds with claims (e.g., Wolfensberger, 1972) that the preschool age would be the most ideal age for inclusion of children with EOD. With the exception of HEALTHY children, all health status groups attended childcare more often than expected with rates of childcare use between 50-60\% for each health status group. In opposition to the expectation, children with NDD and children with EXTBEH had higher percentages of children attending childcare than HEALTHY children. The higher rates of childcare use by children with EOD could be explained 
by the unexpectedly high rates of working PMK's. Perhaps over time, society has come to respect the inclusion rights of the individuals with EOD (Office of the United Nations High Commissioner for Human Rights, 1989) which in turn has allowed for more mothers of children with EOD to work. As expected, children with BOTH had the smallest percentage of children attending childcare.

Although there was an unexpected significant difference between the types of childcare used for each health status group, the only children that were unique in the type of childcare used were children with NDD. These children were the only children, with or without EOD, who most often attended childcare that was not centre based childcare. As a group, children with EOD attended childcare more often than expected however; it was still found that they had the fewest hours per week in childcare. In addition, they had the fewest number of childcare arrangements, entered childcare the latest, and had the poorest level of perceived quality. It should be noted however, that although not all of these differences were significantly different from HEALTHY children. Regardless, childcare characteristics can be used to predict cognitive skills in children with EOD, which suggests that childcare might have a protective role against the considerably more severe cognitive delays that might otherwise occur in children with EOD (Odom, 2000).

For children with EOD, the earlier they entered childcare, the better effect it had on their cognitive development skills. However, the type of childcare also impacted on their cognitive outcomes. If a child with EOD was in care in someone else's home by a relative or non relative, or in care in their own home by a relative or non relative, their scores on the Who am I? test are lower than if the child attended a childcare centre. The difference between the types of childcare might actually have reflected that the childcare providers who have formal training in childcare and experience working with children with EOD might provide a more cognitively stimulating 
environment than childcare workers with no such training and experience. This is of particular concern for children with NDD as, in this study they were the only children who most often had care provided in someone else's home by a relative or non relative, rather than in a childcare centre/preschool.

The type of childcare and the effect it has on the cognitive development of a child with EOD identifies an additional barrier to finding childcare for these children. The current research indicated that if the parents of a child with EOD want to have the most beneficial type of childcare for their child, their child should be in centre based care. However, centre based care tends to be more expensive, further adding to the challenges for those parents with lower family incomes. Moreover, centre based care is often in high demand and can result in long waiting times until a spot is available. Thus, parents may be forced to have childcare provided in an environment other than centre based care.

Results confirmed the prediction that there would be a significant difference between the quantities of childcare per week for each health status group (Booth-LaForce \& Kelly, 2004). Within children with EOD, children with EXTBEH attended significantly less childcare per week than HEALTHY children, although there was no significant difference between the other children with EOD and HEALTHY children. Children with EXTBEH entered childcare at significantly older ages than children who were HEALTHY. Children with NDD entered childcare at the oldest age although this difference was not significant when compared to HEALTHY children.

Finally, the differences in the quality of childcare between children who were HEALTHY and children with EOD were somewhat surprising, in that children with EOD had some of the lower levels of quality. In particular, there were significant differences between 
children with NDD and HEALTHY children. The latter results were the most plausible, based on the fact that children with NDD were the children who less frequently attended centre based care. Based on the mainstream definition of quality from the literature, centre based care should provide the highest quality of care, since the childcare providers in these locations would be the most likely to have formal training in childcare. In addition, childcare centres would be more likely to be licensed when compared to other non-centre based childcare arrangements. Therefore, when considering the attendance rates at the different types of childcare, it was not surprising that PMK's perceived that their children received the lowest level of childcare quality. However, it is important to point out that the quality of childcare was based on self-report and only reflect PMK's perceptions. Therefore, one cannot confidently conclude that the actual quality of childcare was low.

\section{Outcome Variables}

As expected, by and large the family variables had a more significant impact on the outcome variables than the childcare variables (Eunice Kennedy Shriver National Institute of Child Health and Human Development, 2006; NICHD Early Child Care Research Network, 2005). However it was surprising to find that the quality of the childcare was not significantly related to the outcome variables. When quality was examined along with the other childcare variables it was found that it regularly contributed less unique variance than some of the other childcare characteristics such as type of childcare. The null effect was consistently found across both the language and the cognitive outcome measures for all health status groups, except for children with NDD, the childcare quality to which this latter group was exposed to, contributed the most unique variance ( $2 \%)$ for the language outcome. Interestingly, for children with EOD, childcare was significantly related to the cognitive outcomes (Who am I?) but not the language 
outcomes. The reverse effect was found in children who were HEALTHY, in that childcare was significantly related to language but not to cognitive outcomes. More precisely, in some instances, childcare was significantly related to the outcome measures when it was examined only by itself, but was no longer significant when added to the model that held all the family variables constant (children who were HEALTHY or NCH and children with EXTBEH had significant effects of childcare that were then diminished or nullified in the full model for PPVT, Who am I?, or both). At least in these specific situations, it would suggest that there is a possibility that the family variables influence the effect of childcare on the outcome variables.

Although the childcare variables did not impact children that were HEALTHY as much as family variables, they were still a significant predictor of language scores. Furthermore, in children with EOD, both family variables and childcare variables influenced a child's outcomes, although cognitive skills were more related to childcare variables than family variables. Finally, even though family variables predicted scores on language and cognitive outcomes, in some situations more than childcare, the influence of childcare cannot be ignored. Over half of the children in Canada utilize childcare so it is imperative to understand the influence that childcare has on children with and without EOD. Moreover, it is imperative to study the relationship between family and childcare variables and how these relationships influence outcomes in both children with and without EOD.

Policy makers should consider these findings and contemplate if there are ways to make childcare, which occurs in settings other than centres, have a more positive impact on child development. It may be that childcare providers with formal training are offered additional funding to support a child with EOD when compared to the funding provided to childcare providers with no formal training. In addition, early detection and early inclusion should be 
considered as key issues seeing as the impact that childcare has on cognitive outcomes diminish with later ages of entry into childcare.

As implied by Bronfenbrenner (1979), this research highlights the intermingling of different components of a child's life and development. Although some of the results in this study were not anticipated, they do follow a somewhat progressive pattern. For example although children with NDD had a mother that was educated on average as much as HEALTHY children and lived in families that had incomes similar to that of children that are HEALTHY, children with NDD attended the least amount of childcare. This could be related to the fact that children with NDD tended to live in larger families so the mother of these children might be staying home with all the children rather than absorbing the financial cost of childcare. It has been documented that family variables contribute more to a child's developmental outcomes than childcare (Eunice Kennedy Shriver National Institute of Child Health and Human Development, 2006; NICHD Early Child Care Research Network, 2005) such that children with parents that are more educated and make more money, have better outcomes. Finally, this research was in line with the findings from previous research which outlined that children from families with lower family incomes and a lower quality home environment benefitted more from childcare than children with higher family incomes and higher quality home environments (Votruba-Drzal et al., 2004; Watamura et al., 2011). It is possible, that childcare, when attended, builds on the already positive family characteristics in children with NDD, to create a more favourable outcome. For example, childcare may help to "give a break" to parents dealing with the stress of difficult living situations. In addition, it is possible that childcare, when attended in a centre based environment, can help to overcome the potential negative family characteristics that might be experienced by some children with EOD. 
The findings from this research are important in that it is Canadian based and that it focused on children with EOD, something most other research surrounding childcare did not address. However, some limitations of this research should be noted. Most importantly, the quality of childcare had much less of an effect than expected; this was likely due to the way that quality was defined in this study. Other research that found more substantial effects of childcare quality used different criteria for quality, for example, the process quality questions that existed in previous versions of the NLSCY (cycle 4) such as "How often does your caregiver: plan activities and use toys and other materials to help your child learn new things" (Statistics Canada and Human Resources Development Canada, 2004). As with the inclusive definition of EOD, it is possible that if this study were conducted again using process quality questions then the results might be very different. In addition, the present study is cross-sectional and therefore the historical context and generation of the PMK's are different from those in previous cycles (Bronfenbrenner, 2005). Consequently the PMK self reports of perceived quality might be capturing different phenomena. In some circumstances, as quality increased, the scores on the PPVT and Who am I? decreased. This was quite surprising as quality is often linked to better child developmental outcomes (Booth \& Kelly, 2002; Loeb et al., as cited in Parish et al., 2005). If the above supplementary process quality variables were added, as well as other childcare questions such as the childcare placement being for profit or not for profit, the childcare variables might have had a stronger relationship with the language and cognitive outcome variables, specifically quality might have accounted for more unique variance. Future research should take into account these limitations and consider using a more specific sample of children with EOD, redefine quality, or include different variables that might allow for stronger results. Finally, it should be noted that no causal relationship can be drawn from these findings. For 
example, do children with NDD have their specific pattern of childcare use (enter childcare later, spend less time in childcare per week, and have the worst quality of childcare) because their mothers are choosing to stay home, or are their mothers not staying home voluntarily but rather staying home as a result of the lack of appropriate childcare?

Existing research has indicated that family variables were better predictors of a child's developmental outcomes than childcare variables (Eunice Kennedy Shriver National Institute of Child Health and Human Development, 2006; NICHD Early Child Care Research Network, 2005). In addition, Bronfenbrenner (1979) showed that a child's development is influenced by many environments, including the Microsystems (family, peer and childcare), Mesosystems (familychildcare interactions) and Exosystems (family variables such as PMK employment). The current research confirmed the research by the NICHD in that family factors were significant predictors of a child's language and cognitive outcomes. Booth-LaForce \& Kelly (2004) attempted to show that children with EOD had different childcare characteristics when compared to HEALTHY children. However, the study was conducted in the US and the researchers (Booth-LaForce \& Kelly, 2004) did not examine how childcare affected the development of children with EOD. The current research addressed both childcare characteristics and the influence that childcare had on the language and cognitive outcomes in children with EOD. The results indicated that family variables could predict language and cognitive outcomes for children who were HEALTHY and $\mathrm{NCH}$, while childcare variables could predict cognitive outcomes for children with EOD. This confirmed Bronfenbrenner's (1979) hypothetical construct that environments are constantly intermingling, however, the current research also highlighted that the environments had different impacts on developmental outcomes for children with and without EOD. Children who were HEALTHY were more influenced by the family Microsystems and Exosystems than the 
childcare Microsystems and the family-childcare Mesosystem. In contrast, for cognitive outcomes, children with EOD were more influenced by the childcare Microsystems and familychildcare Mesosystems.

We have demonstrated that in a sample representative of the Canadian population of children aged $0-5$, childcare characteristics have a bigger influence on children with EOD than HEALTHY children. It is critical to continue this line of research as the majority of current research is restricted to typically developing children and does not properly represent children with Early Observable Differences. 


\section{References}

Allen, D. (2008). The relationship between challenging behaviour and mental ill-health in people with intellectual disabilities: A review of current theories and evidence. Journal of Intellectual Disabilities, 12, 267-294.

Andrew Fleck Child Care Services (2008). Children's integration support services: Eligibility criteria. Retrieved from http://www.afchildcare.on.ca/cisseligj-e.html

Baker-Ericzen, M. J., Mueggenborg, M. G., \& Shea, M. M. (2009). Impact of trainings on child care providers' attitudes and perceived competence toward inclusion: What factors are associated with change? Topics in Early Childhood Special Education, 28, 196-208. doi: $10.1177 / 0271121408323273$.

Beach, J., Friendly, M., Ferns, C., Prabhu, N., \& Forer, B. (2009). Early childhood education and care in Canada 2008, ( $8^{\text {th }}$ ed.). Toronto, ON: Childcare Resource and Research Unit.

Brandon, P. (2000). Child care utilization among working mothers raising children with disabilities. Journal of Family and Economic Issues, 21, 343-363.

Bronfenbrenner, U. (1979). The ecology of human development: Experiments by nature and design. Cambridge, MA: Harvard University Press.

Bronfenbrenner, U. (2005). Making human beings human: Bioecological perspectives on human development. Thousand Oaks, CA: Sage.

Bruder, B., \& Brand, M. (1995). A comparison of two types of early intervention environments serving toddler-age children with disabilities. The Transdisciplinary Journal, 5, 207-217.

Booth, C. L., \& Kelly, J. F. (2002). Child care effects on the development of toddlers with special needs. Early Childhood Research Quarterly, 17, 171-196.

Booth-LaForce, C., \& Kelly, J. F. (2004). Childcare patterns and issues for families of preschool children with disabilities. Infants and Young Children, 17, 5-16. 
Bushnik, T. (2006). Child care in Canada (Report No. 89-599-MIE - No. 003). Ottawa, ON: Special Surveys Statistics Canada.

Buysse, V., Wesley, P. W., Bryant, D., \& Gardner, D. (1999). Quality of early childhood programs in inclusive and noninclusive settings. Exceptional Children, 65, 301-314.

Campbell, T. C. (2005). Research methods: An introduction to clinical significance: An alternative index of intervention effect for group experimental designs. Journal of Early Intervention, 27, 210-227.

Cohen, J. (1988). Statistical power for the behavioral sciences (2nd ed.). Hillsdale, NJ: Erlbaum.

Cohen, J., Cohen, P., West, S. G., \& Aiken, L. S. (2003). Applied multiple regression correlation (3rd ed.). Mahwah, NJ: Lawrence Erlbaum Associates.

Council of Canadians with Disabilities. (2011). Canada ratifies United Nations Convention on the Rights of Persons with Disabilities. Winnipeg, MB: Council of Canadians with Disabilities. Retrieved from http://www.ccdonline.ca/en/

Cuskelly, M., Pulman, L., \& Hayes, A. (1998). Parenting and employment decisions of parents with a preschool child with a disability. Journal of Intellectual \& Developmental Disability, 23, 319-332.

Cutler, A., Gilkerson, L. S. (2002). Unmet needs project: A research, coalition building, and policy initiative on the unmet needs of infants, toddlers, and families: Final report. Chicago, Illinois: Erikson Institute and University of Illinois at Chicago.

De Lemo, M., and Doig, B. (2000). Who Am I? Developmental Assessment. Melbourne, Australia: Acer Press. Retrieved from https://shop.acer.edu.au/acer-shop/group/WHO Delgado, C. E. F. , Vagi, S. J., \& Scott, K. G. (2007). Identification of early risk factors for developmental delay. Exceptionality, 15, 119-136. 
Dunn, L.M., \& Dunn, L.M. (1981). Peabody Picture Vocabulary Test-Revised. Circle Pines, MN: American Guidance Service.

Elementary Teachers' Federation of Ontario. (2008). Full-day kindergarten: Moving Ontario forward. Early Teacher's Federation of Ontario: Canada. Retrieved from http://www.etfo.ca/Publications/PositionPapers/Documents/FullDay\%20Kindergarten\%20-\%20Moving\%20Ontario\%20Forward.pdf

Emerson, E. (2001). Challenging behaviour: Analysis and intervention in people with severe intellectual disabilities. Cambridge: Cambridge University Press.

Essa, L. E., Bennet, P. R., Burnham, M., Martin, S. S., Bingham, A., \& Allred, K. (2008). Do variables associated with quality child care programs predict the inclusion of children with disabilities? Topics in Early Childhood Special Education, 28, 171-180. doi: $10.1177 / 0271121408324447$

Eunice Kennedy Shriver National Institute of Child Health and Human Development (2006). The NICHD Study of Early Child Care and Youth Development (SECCYD): Findings for Children up to Age 4 1/2 Years. Washington, DC: U.S. Government Printing Office. Feeny, D., Furlong, W., Boyle, M., \& Torrance, G.W. (1995). Multi-Attribute health status classification system: Health Utilities Index. Pharmacoeconomics, 7, 490-502.

Ferleger, D., \& Boyd, P. A. (1980). Anti-institutionalization: The promise of the pennhurst case. In R.J. Flynn and K.E. Nitsch (Eds.), Normalization, social integration, and community services (pp. 141-166). Baltimore: University Park Press.

Friendly, M. \& Prentice, S. (2009). About Canada: Childcare. Winnipeg, MB: Fernwood Publishing. 
Friendly, M., Rothman, L., \& Oloman, M. (1991) Child care for Canadian children and families: Occasional paper no. 1. Prepared for Canada's Children: The Priority for the 90s, A national symposium held by the Child Welfare League of America/Canada, Ottawa, ON.

Government of British Columbia (2010). Full day kindergarten program guide. British Columbia: Ministry of Education.

Green, S. B. (1991). How many subjects does it take to do a regression analysis? Multivariate Behavioral Research, 26, 499-510.

Hartley, S. L., Barker, E. T., Seltzer, M. M., Floyd, F., Greenberg, J., Orsmo, G., \& Bolt, D. (2010). The relative risk and timing of divorce in families of children with an Autism Spectrum Disorder. Journal of Family Psychology, 24, 449-457.

Hemmings, C. (2007). The relationship between challenging behaviours and psychiatric disorders in people with severe intellectual disabilities. In N. Bouras \& G. Holt (Eds.), Psychiatric and behavioural disorders in the intellectual and developmental disabilities (pp. 62-75). Cambridge: Cambridge University Press.

Ingersoll, B., Schreibman, L., \& Stahmer, A. (2001). Brief report: Differential treatment outcomes for children with autism spectrum disorder based on level of peer social avoidance. Journal of Autism and Developmental Disorders, 31, 343-349.

Irwin, S. H., Brophy, K., \& Lero, D. (2000). Literature review: The roles of staff attitude, experience, and training in effective inclusion in child care. In S. H. Irwin, D. S. Lero, \& K. Brophy (Eds.), A matter of urgency: Including children with special needs in child care in Canada (pp.35-54). Wreck Cove, NS: Breton Books. 
Irwin, S. H., \& Lero, D. S. (2001). In the absence of policy: Moving towards inclusion of children with special needs in Canada's childcare centres. In S. Prentice (Eds.), Changing childcare: Five decades of childcare advocacy \& policy in Canada (pp. 153-169). Halifax: Fernwood Publishing.

Irwin, S. H., Lero, D. S., \& Brophy, K. (2000). A matter of Urgency: Including children with special needs in child care in Canada. Wreck Cove, NS: Breton Books.

Irwin, S. H., Lero, D. S., \& Brophy, K. (2004). Inclusion: The next generation in child care in Canada. Wreck Cove, NS: Breton Books.

Kelly, J. F. \& Booth, C. L. (2002). The early child care study of children with special needs. International Review of Research in Mental Retardation, 25, 71-106.

Kagan, C., Lewis, S., Heaton, P., \& Cranshaw, M. (1999). Enabled or Disabled? Working parents of disabled children and the provision of child-care. Journal of Community \& Applied Social Psychology, 9, 369-381.

Kleinbaum, D. G., Kupper, L. L., Nizam, A., \& Muller, K. E. (2008). Applied regression analysis and other multivariate methods ( $4^{\text {th }}$ ed.). Belmont, CA: Thomson Higher Education.

Kutner, M. H., Nachtsheim, C. J., Neter, J., \& Li, W. (2005). Applied linear statistical model, ( $5^{\text {th }}$ ed.) New York, NY: McGraw-Hill Irwin.

Lach, L. M., Kohen, D. E., Garner, R. E., Brehaut, J. C., Miller, A. R., Klassen, A. F...Rosenbaum, P. L. (2009). The health and psychosocial functioning of caregivers of children with neurodevelopmental disorders. Disability and Rehabilitation, 31, 607-618.

Landis, J. L. (1992). Marital, employment and childcare status of mothers with infants and toddlers with disabilities. Topics in Early Childhood Special Education, 12, 496-507. 
Lero, D. S., Doherty, G., Goelman, H., LaGrange, A., \& Tougas, J. (2000). A profile of child care centres across Canada. In G. Doherty, D.S. Lero, H. Goelman, A. LaGrange, \& J. Tougas (Eds.), You bet I care! A Canada wide study on wages, working conditions, and practices in child care centres (pp. 111-124). Guelph, ON: Centre for Families, Work and Well-Being University of Guelph.

Livingston, Z. S. (2010). A study of the academic progress of students with disabilities in urban public middle schools in Georgia (Doctoral Dissertation). Retrieved from Pro-Quest Dissertation and Theses. (UMI 3409188).

McGee, G. G, Morrier, M. J., \& Daly, T. (1991). An incidental teaching approach to early intervention for toddlers with autism. The Journal of the Association for Persons with Severe Handicaps, 24, 133-146.

Mulvihill, B. A., Shearer, D., \& Van Horn, M. L. (2002). Training, experience, and child care providers' perceptions of inclusion. Early Childhood Research Quarterly, 17, 197-215.

Najman, J. M., Bor, W., Morrison, J., Andersen, M., \& Williams, G. (1992). Child developmental delay and socio-economic disadvantage in Australia: A longitudinal study. Social Science and Medicine, 34, 829-835.

NICHD Early Child Care Research Network (1999). Child outcomes when child care center classes meet recommended standards for quality. American Journal of Public Health, 89, $1072-1077$.

NICHD Early Child Care Research Network (2005). Child care and child development: Results from the NICHD study of early child care and youth development. New York: Guilford Press. 
Odom, S. L. (2000). Preschool inclusion: What we know and where we go from here. Topics in Early Childhood Special Education, 20, 20-27. doi: 10.1177/027112140002000104

Odom, S. L., Hansen, M. J., Lieber, J., Marquart, J., Sandall, S., Wolery, R., ...Chambers, J. (2001). The cost of preschool inclusion. Topics in Early Childhood Special Education, 21, 46-55. doi: 10.1177/027112140102100104

Odom, S. L., Vitzum, J., Woler, R., Lieber, J., Sandall, S., Hansen, M.J., ...Horn, E. (2004). Preschool inclusion in the United States: A review of research from an ecological systems perspective. Journal of Research in Special Education Needs, 4, 17-49. doi: 10.1111/J.1471-3802.2004.00016.x

Office of the Premier (2011). More Ontario children in full-day kindergarten. Ontario: Queen's Printer for Ontario. Retrieved from http://www.premier.gov.on.ca/news/event.php?ItemID=12679\&Lang=EN

Office of the United Nations High Commissioner for Human Rights. (1989). Convention on the Rights of the Child. New York: United Nations Children's Fund. Retrieved from http://www2.ohchr.org/english/law/pdf/crc.pdf

Office of the United Nations High Commissioner for Human Rights. (2007). Convention on the Rights of Persons with Disabilities. New York: United Nations Children's Fund. Retrieved from http://www.un.org/disabilities/default.asp?id=259

Oliver, M. (1983). Social work with disabled people. London: The Macmillan Press LTD.

Parish, S. L., Cloud, J. M., Huh, J. \& Henning, A. N. (2005). Child care, disability, and family structure: Use and quality in a population-based sample of low-income preschool children. Children and Youth Services Review, 27, 905-919. 
Peck, C., Carlson, P., \& Helmstetter, E. (1992). Parent and teacher perceptions of outcomes for typically developing children enrolled in integrated early childhood programs: A statewide survey. Journal of Early Intervention, 16, 53-63.

Powers, E. T. (2003). Children's health and maternal work activity: Estimates under alternative disability definitions. Journal of Human Resources, 38, 523-556.

Prentice, S. (2001). Changing childcare, looking back, moving forward. In S. Prentice (Eds.), Changing childcare: Five decades of childcare advocacy \& policy in Canada (pp. 1526). Halifax: Fernwood Publishing.

Rojahn, J., Aman, M. G., Marshburn, E., Moeschberger, M. L., King, E. H., Logsdon, D. A., Schroeder, S. R. (1993). Biological and environmental risk for poor developmental outcome for young children. American Journal on Mental Retardation, 97, 702-708.

Romano, E., Kohen, D., Findlay, L. (2010). Associations among child care, family, and behavior outcomes in a nation-wide sample of preschool-aged children. International Journal of Behavioral Development, 34, 427-440.

Rosenzweig, J. M., Brennan, E. M., Huffstutter, K., \& Bradley, J. R. (2008). Child care and employed parents of children with emotional or behavioral disorders. Journal of Emotional and Behavioral Disorders, 16, 78-89. doi: 10.1177/1063426607312538

Rosenzweig, J. M., Brennan, E. M., \& Ogilvie, A. M. (2002). Work-family fit: Voices of parents of children with emotional and behavioral disorders. Social Work, 47, 415-424.

Service Canada (2011). Employment Insurance (EI) and maternity, parental and sickness benefits. Retrieved from http://www.servicecanada.gc.ca/eng/ei/types/special.shtml\#Parental3 
Shakuntala Walker, J. \& Melvin, J.K. (2011). Emotional Disorders (In Children and Adolescents). In: JH Stone, M Blouin (Eds.), International Encyclopedia of Rehabilitation. Buffalo, NY: Center for International Rehabilitation Research Information and Exchange. Retrieved from http://cirrie.buffalo.edu/encyclopedia/en/article/7/

Shearn, J., \& Todd, S. (2000). Maternal employment and family responsibilities: The prospective of mothers of children with intellectual disabilities. Journal of Applied Research in Intellectual Disabilities, 13, 109-131.

Shpancer, N. (2006). The effects of daycare: Persistent questions, elusive answers. Early Childhood Research Quarterly, 21, 227-237.

Sigafoos, J., Arther, M., \& O’Reilly, M. (2003). Challenging behaviour and developmental disability. London: Whurr.

Simes, R. J. (1986). An improved Bonferroni procedure for multiple tests of significance. Biometrika, 73, 751-754.

Smith, K. (2002). Who's minding the kids? Child care arrangements: Spring 1997. Current Population Reports (pp. 70-86). Washington, DC: U.S. Census Bureau. Retrieved from http://www.census.gov/prod/2002pubs/p70-86.pdf

Sonenstein, F. L., Gates, G. J., Schmidt, S., \& Bolshun, N. (2002). Primary child care arrangements of employed parents: Findings from the 1999 National Survey of America's Families (Occasional paper Number 59). Washington, DC: Urban Institute.

Stahmer, A. C., \& Carter, C. (2005). An empirical examination of toddler development in inclusive childcare. Early Child Development and Care, 4, 321-333. 
Stahmer, A. C., Carter, C., Baker, M., \& Miwa, K. (2003). Parent perspectives on their toddlers development: Comparison of regular and inclusive childcare. Early Child Development and Care, 5, 477-488.

Statistics Canada (2004). Cycle4 (2004-2005) user's guide. Ottawa, ON: Statistics Canada. Statistics Canada (2006a). Cycle7 (2006-2007) user's guide. Ottawa, ON: Statistics Canada. Statistics Canada (2006b). Participation and Activity Limitation Survey 2006. Ottawa, ON: Minister of Industry.

Statistics Canada and Human Resources Development Canada (2006a). National Longitudinal Survey of Children and Youth: Overview of survey instruments for 2006-2007 data collection cycle 7. Ottawa, ON: Statistics Canada and Human Resources Development Canada.

Statistics Canada and Human Resources Development Canada (2006b). National Longitudinal Survey of Children and Youth, Cycle 7, 2006 Master file: Early Childhood Development. Ottawa, ON: Statistics Canada and Human Resources Development Canada.

Stevens, J. (2002). Applied multivariate statistics for the social sciences $\left(4^{\text {th }} \mathrm{ed}\right.$.). Mahwah, NJ: Lawrence Erlbaum Associates.

Tabachnick, B. G., \& Fidell, L. S. (2006). Using multivariate statistics $\left(5^{\text {th }}\right.$ ed.) Needham Heights, MA: Allyn \& Bacon, Inc.

UNICEF (2008). The child care transition: Innocenti report card 8. Florence, Italy: UNICEF Innocenti Research Centre. Retrieved from http://www.unicef.ca/portal/Secure/Community/502/WCM/HELP/take_action/Advocacy/ rc8.pdf 
Votruba-Drzal, E., Coley, R. L., \& Chase-Lansdale, L. (2004). Childcare and low-income children's development: Direct and moderated effects. Child Development, 75, 296-312.

Watamura, S. E., Morrissey, T. W., Phillips, D. A., McCartney, K., \& Bub, K. (2011). Double jeopardy: Poorer socio-emotional outcomes for children in the NICHD SECCYD experiencing home and child-care environments that confer risk. Child Development, 82, 48-65.

Winsler, A., \& Wallace, G.L. (2002). Behavior problems and social skills in preschool children: Parent teacher agreement and relations with classroom observations. Early Education and Development, 13, 41-58.

Wolfensberger, W. (1972). The principles of normalization in human services. Canada: National Institute on Mental Retardation.

Wymbs, B. T., Pelham, W. E., Molina, B. S. G., Gnagy, E. M., Wilson, T. K., \& Greenhouse, J. B. (2008). Rate and predictors of divorce among parents of youths with ADHD. Journal of Consulting and Clinical Psychology, 76, 735-744. 


\section{Appendix}

\section{PPVT Regression Results}

Table A1. 1

Regression of Family and Childcare variables for full model on PPVT

Model Summary

\begin{tabular}{|c|c|c|c|c|c|c|c|c|c|c|}
\hline & \multirow[b]{2}{*}{ Model } & \multirow[b]{2}{*}{$\mathrm{R}$} & \multirow[b]{2}{*}{$\begin{array}{c}\mathrm{R} \\
\text { Square }\end{array}$} & \multirow[b]{2}{*}{$\begin{array}{l}\text { Adjusted } \\
\text { R Square }\end{array}$} & \multirow[b]{2}{*}{$\begin{array}{l}\text { Std. Error } \\
\text { of the } \\
\text { Estimate }\end{array}$} & \multicolumn{5}{|c|}{ Change Statistics } \\
\hline & & & & & & $\begin{array}{c}\text { R } \\
\text { Square } \\
\text { Change }\end{array}$ & $\begin{array}{c}F \\
\text { Change }\end{array}$ & df1 & $\mathrm{df} 2$ & $\begin{array}{c}\text { Sig. F } \\
\text { Change }\end{array}$ \\
\hline \multirow[t]{2}{*}{ NDD group } & 1 & $.341^{\mathrm{a}}$ & .116 & .054 & 13.858 & .116 & 1.866 & 6 & 85 & .096 \\
\hline & 2 & $.383^{b}$ & .147 & .005 & 14.210 & .031 & .403 & 7 & 78 & .898 \\
\hline \multirow[t]{2}{*}{ EXTBEH } & 1 & $.540^{\mathrm{a}}$ & .291 & .258 & 10.912 & .291 & 8.705 & 6 & 127 & .000 \\
\hline & 2 & $.557^{\mathrm{b}}$ & .311 & .236 & 11.071 & .019 & .484 & 7 & 120 & .845 \\
\hline \multirow[t]{2}{*}{ HEALTHY } & 1 & $.252^{\mathrm{a}}$ & .064 & .056 & 13.561 & .064 & 8.364 & 6 & 737 & .000 \\
\hline & 2 & $.289^{b}$ & .084 & .067 & 13.481 & .020 & 2.254 & 7 & 730 & .028 \\
\hline \multirow[t]{2}{*}{$\mathrm{NCH}$} & 1 & $.315^{\mathrm{a}}$ & .099 & .071 & 12.347 & .099 & 3.561 & 6 & 194 & .002 \\
\hline & 2 & $.379^{\mathrm{b}}$ & .144 & .084 & 12.260 & .045 & 1.397 & 7 & 187 & .209 \\
\hline
\end{tabular}

a. Predictors: (Constant), Age of child, numsib, dummysingleparent, LICO, Hourswork, PMKeducation

b. Predictors: (Constant), Age of child, numsib, dummysingleparent, LICO, Hourswork, PMKeducation, ageentry, numarrag, dummyelse, qualityfinal, dummyown, hours, dummyother 


\section{ANOVA}

\begin{tabular}{|c|c|c|c|c|c|c|c|}
\hline \multirow{2}{*}{ NDD group } & \multicolumn{2}{|c|}{ Model } & \multirow{2}{*}{$\frac{\text { Sum of Squares }}{2149.796}$} & \multirow{2}{*}{$\frac{\mathrm{Df}}{6}$} & \multirow{2}{*}{$\begin{array}{r}\text { Mean Square } \\
358.299\end{array}$} & \multirow{2}{*}{$\frac{F}{1.866}$} & \multirow{2}{*}{$\frac{\text { Sig. }}{.096^{\mathrm{a}}}$} \\
\hline & 1 & Regression & & & & & \\
\hline & & Residual & 16375.880 & 85 & 192.032 & & \\
\hline & & Total & 18525.677 & 91 & & & \\
\hline & 2 & Regression & 2719.479 & 13 & 209.191 & 1.036 & $.427^{\mathrm{b}}$ \\
\hline & & Residual & 15806.198 & 78 & 201.926 & & \\
\hline & & Total & 18525.677 & 91 & & & \\
\hline \multirow[t]{6}{*}{ EXTBEH } & 1 & Regression & 6219.296 & 6 & 1036.549 & 8.705 & $.000^{\mathrm{a}}$ \\
\hline & & Residual & 15131.930 & 127 & 119.081 & & \\
\hline & & Total & 21351.226 & 133 & & & \\
\hline & 2 & Regression & 6634.633 & 13 & 510.356 & 4.164 & $.000^{\mathrm{b}}$ \\
\hline & & Residual & 14716.592 & 120 & 122.565 & & \\
\hline & & Total & 21351.226 & 133 & & & \\
\hline \multirow[t]{6}{*}{ HEALTHY } & 1 & Regression & 9228.265 & 6 & 1538.044 & 8.364 & $.000^{\mathrm{a}}$ \\
\hline & & Residual & 135593.961 & 737 & 183.900 & & \\
\hline & & Total & 144822.226 & 743 & & & \\
\hline & 2 & Regression & 12095.685 & 13 & 930.437 & 5.120 & $.000^{\mathrm{b}}$ \\
\hline & & Residual & 132726.541 & 730 & 181.736 & & \\
\hline & & Total & 144822.226 & 743 & & & \\
\hline \multirow[t]{6}{*}{$\mathrm{NCH}$} & 1 & Regression & 3256.917 & 6 & 542.820 & 3.561 & $.002^{\mathrm{a}}$ \\
\hline & & Residual & 29637.175 & 194 & 152.452 & & \\
\hline & & Total & 32894.092 & 200 & & & \\
\hline & 2 & Regression & 4726.799 & 13 & 363.600 & 2.419 & $.005^{\mathrm{b}}$ \\
\hline & & Residual & 28167.293 & 187 & 150.303 & & \\
\hline & & Total & 32894.092 & 200 & & & \\
\hline
\end{tabular}

a. Predictors: (Constant), Age of child, numsib, dummysingleparent, LICO, Hourswork, PMKeducation b. Predictors: (Constant), Age of child, numsib, dummysingleparent, LICO, Hourswork, PMKeducation, ageentry, numarrag, dummyelse, qualityfinal, dummyown, hours, dummyother 


\section{Who am I? regression results}

Table A1. 2

Regression of Family and Childcare variables for full model on Who am I?

\section{Model Summary}

\begin{tabular}{|c|c|c|c|c|c|c|c|c|c|c|}
\hline & \multirow[b]{2}{*}{ Model } & \multirow[b]{2}{*}{$\mathrm{R}$} & \multirow[b]{2}{*}{$\begin{array}{c}\mathrm{R} \\
\text { Square }\end{array}$} & \multirow[b]{2}{*}{$\begin{array}{l}\text { Adjusted } \\
\text { R Square }\end{array}$} & \multirow[b]{2}{*}{$\begin{array}{l}\text { Std. Error } \\
\text { of the } \\
\text { Estimate }\end{array}$} & \multicolumn{5}{|c|}{ Change Statistics } \\
\hline & & & & & & $\begin{array}{c}\mathrm{R} \\
\text { Square } \\
\text { Change }\end{array}$ & $\begin{array}{c}\mathrm{F} \\
\text { Change }\end{array}$ & df1 & $d f 2$ & $\begin{array}{l}\text { Sig. F } \\
\text { Change }\end{array}$ \\
\hline \multirow[t]{2}{*}{ NDD group } & 1 & $.370^{\mathrm{a}}$ & .137 & .077 & 15.494 & .137 & 2.286 & 6 & 86 & .043 \\
\hline & 2 & $.565^{\mathrm{b}}$ & .320 & .208 & 14.352 & .183 & 3.040 & 7 & 79 & .007 \\
\hline \multirow[t]{2}{*}{ EXTBEH } & 1 & $.306^{\mathrm{a}}$ & .094 & .050 & 16.068 & .094 & 2.142 & 6 & 124 & .053 \\
\hline & 2 & $.480^{\mathrm{b}}$ & .230 & .144 & 15.249 & .136 & 2.956 & 7 & 117 & .007 \\
\hline \multirow[t]{2}{*}{ HEALTHY } & 1 & $.288^{\mathrm{a}}$ & .083 & .075 & 14.565 & .083 & 11.081 & 6 & 737 & .000 \\
\hline & 2 & $.299^{\mathrm{b}}$ & .089 & .073 & 14.583 & .006 & .739 & 7 & 730 & .639 \\
\hline \multirow[t]{2}{*}{$\mathrm{NCH}$} & 1 & $.471^{\mathrm{a}}$ & .221 & .196 & 15.050 & .221 & 8.809 & 6 & 185 & .000 \\
\hline & 2 & $.520^{\mathrm{b}}$ & .270 & .217 & 14.851 & .049 & 1.715 & 7 & 178 & .108 \\
\hline
\end{tabular}




\section{ANOVA}

\begin{tabular}{|c|c|c|c|c|c|c|c|}
\hline & Model & & $\begin{array}{l}\text { Sum of } \\
\text { Squares }\end{array}$ & Df & Mean Square & $\mathrm{F}$ & Sig. \\
\hline \multirow[t]{6}{*}{ NDD group } & 1 & Regression & 3292.994 & 6 & 548.832 & 2.286 & $.043^{\mathrm{a}}$ \\
\hline & & Residual & 20717.182 & 86 & 240.061 & & \\
\hline & & Total & 24010.176 & 92 & & & \\
\hline & 2 & Regression & 7675.827 & 13 & 590.448 & 2.866 & $.002^{b}$ \\
\hline & & Residual & 16334.349 & 79 & 205.983 & & \\
\hline & & Total & 24010.176 & 92 & & & \\
\hline \multirow[t]{6}{*}{ ЕХTВEH } & 1 & Regression & 3317.856 & 6 & 552.976 & 2.142 & $.053^{\mathrm{a}}$ \\
\hline & & Residual & 32034.032 & 124 & 258.190 & & \\
\hline & & Total & 35351.889 & 130 & & & \\
\hline & 2 & Regression & 8129.726 & 13 & 625.364 & 2.689 & $.002^{\mathrm{b}}$ \\
\hline & & Residual & 27222.162 & 117 & 232.526 & & \\
\hline & & Total & 35351.889 & 130 & & & \\
\hline \multirow[t]{6}{*}{ HEALTHY } & 1 & Regression & 14104.244 & 6 & 2350.707 & 11.081 & $.000^{\mathrm{a}}$ \\
\hline & & Residual & 156413.027 & 737 & 212.133 & & \\
\hline & & Total & 170517.271 & 743 & & & \\
\hline & 2 & Regression & 15204.819 & 13 & 1169.601 & 5.500 & $.000^{\mathrm{b}}$ \\
\hline & & Residual & 155312.452 & 730 & 212.659 & & \\
\hline & & Total & 170517.271 & 743 & & & \\
\hline \multirow[t]{6}{*}{$\mathrm{NCH}$} & 1 & Regression & 11970.772 & 6 & 1995.129 & 8.809 & $.000^{\mathrm{a}}$ \\
\hline & & Residual & 42088.944 & 186 & 226.490 & & \\
\hline & & Total & 54059.716 & 192 & & & \\
\hline & 2 & Regression & 14618.870 & 13 & 1124.528 & 5.099 & $.000^{\mathrm{b}}$ \\
\hline & & Residual & 39440.846 & 179 & 220.548 & & \\
\hline & & Total & 54059.716 & 192 & & & \\
\hline
\end{tabular}

a. Predictors: (Constant), Age of child, numsib, dummysingleparent, LICO, Hourswork, PMKeducation

b. Predictors: (Constant), Age of child, numsib, dummysingleparent, LICO, Hourswork, PMKeducation, ageentry, numarrag, dummyelse, qualityfinal, dummyown, hours, dummyother 